\title{
Reactive Oxygen Species and Organellar Signaling
}

Su Yin Phua ${ }^{1,2}$, Barbara De Smet ${ }^{1,2}$, Claire Remacle ${ }^{3}$, Kai Xun Chan ${ }^{1,2 *}$, Frank Van Breusegem $^{1,2 *}$

ORCID ID: 0000-0002-7556-1211 (S.Y.P.); 0000-0001-7618-1790 (B.D.S.); 0000-00025016-9547 (C.R.); 0000-0003-3554-7228 (K.X.C.); 0000-0002-3147-0860 (F.V.B.)

${ }^{1}$ Department of Plant Biotechnology and Bioinformatics, Ghent University, 9052 Ghent, Belgium

${ }^{2}$ Center for Plant Systems Biology, VIB, 9052 Ghent, Belgium

${ }^{3}$ Genetics and physiology of microalgae, InBios/Phytosystems, Université de Liège, 4000 Liège, Belgium.

*Correspondence: kaixun.chan@psb.ugent.be; frank.vanbreusegem@psb.ugent.be

E-mails: suyin.phua@psb.ugent.be (S.Y.P); desmet.barbara1@ gmail.com (B.D.S.);

c.remacle@uliege.be (C.R.); kaixun.chan@psb.ugent.be (K.X.C.);

frank.vanbreusegem@psb.ugent.be (F.V.B.)

Running Title: ROS and Organellar Signaling

Total word count: $\quad 8138$

Figures: 2 (color online only)

Tables: 0

Supplementary Data: 0 


\section{Highlight}

Reactive oxygen species (ROS) in different organelles (chloroplasts, mitochondria, and peroxisomes) trigger distinct, yet potentially intersecting, organellar signaling pathways that mediate operational readjustments of the respective organelle during environmental stresses. 


\section{Abstract}

2 The evolution of photosynthesis and its associated metabolic pathways has been crucial to the

3 successful establishment of plants, but has also challenged plant cells in the form of reactive

4 oxygen species (ROS) production. Intriguingly, multiple forms of ROS are generated in

5 virtually every plant cell compartment through diverse pathways. As a result, a sophisticated

6 network of ROS detoxification and signaling that is simultaneously tailored to individual

7 organelles and safeguards the entire cell is necessary. Here we take an organelle-centric view

8 on the principal sources and sinks of ROS across the plant cell and give insights into the ROS-

9 induced organelle-to-nucleus retrograde signaling pathways needed for operational

10 readjustments during environmental stresses.

\section{Key words}

13 Chloroplasts, metabolism, mitochondria, peroxisomes, photorespiration, photosynthesis, reactive oxygen species (ROS), retrograde signaling

\section{Abbreviations}

${ }^{1} \mathrm{O}_{2}$, Singlet oxygen; 2PG, 2-phosphoglycolate; 3PGA, 3-phosphoglycerate; APX, ascorbate peroxidase; $\mathrm{CO}_{2}$, carbon dioxide; ETC, electron transport chain; GPX, glutathione peroxidase; $\mathrm{H}_{2} \mathrm{O}_{2}$, hydrogen peroxide; MecPP, methylerythritol cyclodiphosphate; $\mathrm{O}_{2}$, oxygen; $\mathrm{O}_{2}{ }^{*-}$, superoxide anions; OH', hydroxyl radical; PAP, 3'-phosphoadenosine 5'-phosphate; PRX, peroxiredoxins; PSII, photosystem II; ROS, reactive oxygen species; Rubisco, ribulose-1,5bisphosphate carboxylase/oxygenase; SA, salicylic acid; SODs, superoxide dismutases; Trx, thioredoxin; $\beta$-CC, $\beta$-cyclocitral. 


\section{Introduction}

Oxygenic photosynthesis converts solar energy into biochemical energy by splitting water and releasing oxygen $\left(\mathrm{O}_{2}\right)$. This process gradually modified the ancient anaerobic atmosphere [mainly composed of methane, nitrogen, and carbon dioxide $\left(\mathrm{CO}_{2}\right)$, with oxygen levels below $0.1 \%$ ] to the present more oxygen-enriched earth's atmosphere (Holland, 2006; Luo et al., 2016), driving the evolution of aerobic lifestyles. The enrichment in atmospheric oxygen enabled the establishment of the ozone layer, which protects living organisms from harmful UV-radiation. Moreover, the use of oxygen as the final electron acceptor of electron transport chains (ETC) in cellular respiration boosted cellular energy production, yielding up to 15 fold more ATP from carbon sources, such as glucose (Halliwell, 2006).

The increased oxygen abundance within plant cells also came with a trade-off, namely the enhanced production of partially reduced or excited forms of oxygen, collectively known as reactive oxygen species (ROS) [reviewed by Noctor and Foyer (2016); Waszczak et al. (2018)]. ROS are highly reactive and can oxidize various biological molecules, such as DNA, lipid, and proteins, causing cellular damage (Van Breusegem and Dat, 2006). Changes in environmental conditions, such as water availability, light intensity, temperature, and pathogen presence, trigger a surge in ROS production in organelles, such as chloroplasts and mitochondria, resulting in oxidative stress in plants. However, plants can also utilize the reactive properties of ROS to their benefit. For example, in a developmental context, by strategically increasing ROS concentrations at the apoplast to loosen the existing rigid cell wall for cell expansion during growth (Kärkönen and Kuchitsu, 2015) or to kill invading pathogens by launching a NADPH oxidase-dependent oxidative burst (Kadota et al., 2015). A highly sophisticated regulatory network exists in plant cells to sense, respond to, detoxify, and utilize ROS. Intriguingly, recent discoveries highlight a prominent influence of organelle compartmentation on this ROS network. Therefore, this review takes on an organelle-centric view to examine the nature and mode of cellular acclimation to ROS.

\section{ROS metabolism in plant cells}

\section{Unique and common aspects of ROS}


Different ROS have distinct chemical reactivity characteristics that determine their half-lives and migration distance at the cellular level. For a useful summary of ROS types and characteristics, we refer the reader to Tripathy and Oelmüller (2012), Das and Roychoudhury (2014), and Mittler (2017). The hydroxyl radical $\left(\mathrm{OH}^{*}\right)$ is the most reactive of all ROS and, hence, the shortest lived (half-life of $1 \mathrm{~ns})$. Singlet oxygen $\left({ }^{1} \mathrm{O}_{2}\right)$ and superoxide anions $\left(\mathrm{O}_{2}{ }^{\cdot-}\right)$ are relatively longer-lived ROS (half-life of 1-4 $\mu \mathrm{s}$ ) and moderately reactive, although $\mathrm{O}_{2}{ }^{-\cdots}$ is rapidly converted to $\mathrm{H}_{2} \mathrm{O}_{2}$ either by superoxide dismutases (SODs) or via nonenzymatic dismutation (Bielski and Allen, 1977). Consequently $\mathrm{O}_{2}{ }^{\circ-}$ has a relatively shorter migration distance range than ${ }^{1} \mathrm{O}_{2} . \mathrm{H}_{2} \mathrm{O}_{2}$ is considered the most stable ROS with the longest lifetime and can migrate through the cell (in $\mu \mathrm{m}$ range).

With the exception of ${ }^{1} \mathrm{O}_{2}$, which is mostly generated at photosystem II (PSII) in thylakoid membranes of chloroplasts, the other three ROS are found across multiple subcellular compartments. Both $\mathrm{O}_{2}{ }^{\circ-}$ and $\mathrm{H}_{2} \mathrm{O}_{2}$ are produced in mitochondria, chloroplasts, peroxisomes, and the apoplast. $\mathrm{OH}^{-}$is also produced in all of these compartments, because it derives from $\mathrm{H}_{2} \mathrm{O}_{2}$ in an $\mathrm{Fe}^{2+}$-dependent reaction. Similarly, the removal of $\mathrm{O}_{2}{ }^{\cdot{ }^{-}}, \mathrm{H}_{2} \mathrm{O}_{2}$, and $\mathrm{OH}^{*}$ share similar mechanisms across different organelles. For example, each of the subcellular compartments contains at least one member of the SOD family for $\mathrm{O}_{2}{ }^{-*}$ detoxification (Alscher et al., 2002). $\mathrm{H}_{2} \mathrm{O}_{2}$ homeostasis across the different organelles is mainly determined by a core set of ubiquitous redox couples, including ascorbate (DHA/Asc), $\mathrm{NAD}(\mathrm{P})+/ \mathrm{NAD}(\mathrm{P}) \mathrm{H}$, and thiol (-SH, sulfhydryl group)-containing couples, such as thioredoxin (Trx), ferredoxin (Fd), and glutathione (GSH/GSSG). The reduction of these redox couples typically passes through a cycling process of thiol relays with $\mathrm{NAD}(\mathrm{P}) \mathrm{H}$ feeding the cycle with electrons (Mittler et al., 2004). Additionally, $\mathrm{H}_{2} \mathrm{O}_{2}$ can be detoxified by catalases (Mhamdi et al., 2010). The most reactive $\mathrm{OH}^{*}$ is probably scavenged nonenzymatically by nearby sugars and proteins to form less reactive oxidized sugar and protein radicals (Matros et al., 2015; Kumar et al., 2019).

\section{Metabolism is a major ROS source in plants}

Energy metabolism in plant cells not only links chloroplasts, mitochondria, and peroxisomes together in the channeling and conversion of carbon-containing compounds, but also generates ROS as by-products in all three organelles (Fig. 1), although in comparison to mammalian cells, chloroplasts and peroxisomes are considered the major ROS sources in illuminated photosynthetic cells rather than mitochondria (Noctor et al., 2002). The high rate 
of electron and energy transfers within the plant energy organelles are crucial drivers that facilitate ROS production both at the thylakoid membrane of chloroplasts during photosynthetic light reactions and at the mitochondrial inner membrane ETC during cellular respiration (see below).

The second driver for ROS overproduction is the key player in carbon-fixing photosynthesis, ribulose-1,5-bisphosphate carboxylase/oxygenase (Rubisco). The evolution of Rubisco as a $\mathrm{CO}_{2}$-carboxylating enzyme preceded the aforementioned atmospheric oxygenation that occurred over a relatively shorter timescale (Iñiguez et al., 2020). Consequently Rubisco has poor $\mathrm{CO}_{2} / \mathrm{O}_{2}$ discrimination and frequently incorporates $\mathrm{O}_{2}$ rather than $\mathrm{CO}_{2}$ to form 2-phosphoglycolate (2PG) instead of 3-phosphoglycerate (3PGA) in the Calvin-Benson cycle. 2PG can negatively impact on carbon fixation by (i) draining the carbon substrate from the Calvin-Benson cycle, when not recycled and (ii) more importantly, inhibiting enzyme activities, including those of enzymes that function downstream of Rubisco in the Calvin-Benson cycle, such as triose-phosphate isomerase and sedoheptulose 1,7bisphosphate phosphatase (Norman and Colman, 1991; Flügel et al., 2017). To minimize these impacts, $2 \mathrm{PG}$ is rapidly degraded and ultimately converted back to 3PGA via photorespiration, a light-induced biochemical process that consumes $\mathrm{O}_{2}$ and releases $\mathrm{CO}_{2}$ (Hagemann et al., 2016). Photorespiration spans across multiple cellular compartments (chloroplasts, peroxisomes, mitochondria, and cytosol) and ROS in the form of hydrogen peroxide $\left(\mathrm{H}_{2} \mathrm{O}_{2}\right)$ is produced within the peroxisomes via the action of glycolate oxidase (Fig. 1). In cells of $\mathrm{C} 3$ plants, photorespiration is estimated to account for approximately $70 \%$ of the $\mathrm{H}_{2} \mathrm{O}_{2}$ production (Noctor et al., 2002). By contrast, in algae, the oxidation of glycolate is catalyzed either by a glycolate oxidase, as in plants, or by a glycolate dehydrogenase, which does not generate $\mathrm{H}_{2} \mathrm{O}_{2}$. The green microalga Chlamydomonas reinhardtii encodes both enzymes in its genome. Glycolate oxidation is performed by the mitochondria-localized glycolate dehydrogenase while the so-called glycolate oxidase is rather a lactate oxidase (Kern et al., 2020).

\section{Chloroplastic ROS metabolism}

When light intensity exceeds the photosynthetic capacity, photosynthetic organisms trigger different mechanisms to protect their photosynthetic ETC by minimizing production, or increasing the scavenging, of ROS (Müller et al., 2001; Murchie and Ruban, 2020). One prominent set of short-term adaptations, named 'nonphotochemical quenching' (NPQ), is 
associated with PSII (Horton et al., 1996) and include processes, such as (i) state transitions (qT), (ii) high energy-dependent quenching (qE), and (iii) photoinhibition (qI).

State transitions are important for the optimization of the energy distribution between PSI and PSII (Ruban and Johnson, 2009; Stirbet et al., 2020). They are regulated by a kinase [state transition 7 (STT7) in Chlamydomonas and STN7 in higher plants (Rochaix, 2007)] of which the activation requires binding of plastoquinol to the cytochrome b 6 complex (Wollman, 2001). This kinase phosphorylates light-harvesting complex II (LHCII) and the phosphorylated LHCII disconnects from PSII and becomes a PSI antenna (state 2). When the plastoquinone pool is oxidized, the kinase is inactivated, the LHCII is dephosphorylated by a phosphatase (PPHI/TAP38), and moves back to PSII (state 1) [reviewed by (Stirbet et al., 2020)]. Interestingly, qT is very pronounced in cyanobacteria and algae, but is a weaker response in higher plants where it is not associated with a change in gene expression (Ruban and Johnson, 2009).

High energy-dependent quenching (qE) corresponds to the deactivation of the PSII antenna by heat and is induced by three factors: (i) an acidification of the $\mathrm{pH}$ in the lumen, (ii) the xanthophyll cycle that catalyzes the conversion of violaxanthin into antheraxanthin and zeaxanthin, and (iii) a PSII subunit, PsbS (Stirbet et al., 2020). In algae, the qE extent depends on the light-harvesting complex stress-related (LHCSR) proteins (Peers et al., 2009) and to a lesser extent on PsbS (Correa-Galvis et al., 2016).

Photoinhibition (qI) occurs when the other mechanisms cannot alleviate the light stress. It corresponds to damage to D1, the PSII reaction center, produced by singlet oxygen at the acceptor side of PSII or the production of long-lived highly oxidizing P680 at the donor site of PSII (Andersson and Aro, 2001).

It is noteworthy that $\mathrm{qT}, \mathrm{qE}$ and $\mathrm{qI}$ function at different timescales relative to ROS accumulation [reviewed in Dietz (2015)]. Energy quenching via $\mathrm{qE}$ is activated within seconds of exposure to higher light intensity and qT functions over a period of minutes thereafter; whereas qI occurs on a timeframe of hours. Chloroplastic ROS accumulation has been mostly documented to occur within minutes-hours post-exposure to high light; thus $\mathrm{qE}$ and qT most likely prevent ROS accumulation while qI serves to alleviate damage by ROS overaccumulation. This is exemplified by the higher ${ }^{1} \mathrm{O}_{2}$ accumulation in high light stressed $n p q 1$, deficient in the light-dependent violaxanthin to zeaxanthin interconversion component of qE, compared to wild type (Dall'Osto et al., 2012).

As mentioned above, singlet oxygen is commonly produced in the PSII center, when excited chlorophyll molecules react in a triplet state $\left({ }^{3} \mathrm{Chl}\right)$ with oxygen (Fischer et al., 2013) 
rather than when its excess energy is quenched by nearby pigments, such as carotenoids (Fig. 1). Singlet oxygen can also be produced in the presence of biosynthetic intermediates of chlorophyll (protochlorophyllide or protoporphyrin IX), which are photosensitizers, upon light exposure (Wang et al., 2016). Production of ${ }^{1} \mathrm{O}_{2}$ from chlorophyll intermediates can occur either on thylakoid membranes or in the prolamellar body of proplastids and etioplasts of developing seedlings when first exposed to light after germination in soil (Solymosi and Schoefs, 2010). These chlorophyll intermediates are normally kept at low levels under the tight regulation of chlorophyll production to minimize ${ }^{1} \mathrm{O}_{2}$ production in wild type plants. In Arabidopsis thaliana, the flu mutant deficient in rapid light-responsive conversion of protochlorophyllide to avoid ${ }^{1} \mathrm{O}_{2}$ accumulation has served as a valuable tool to elucidate ${ }^{1} \mathrm{O}_{2}$ detoxification and signaling (discussed later). For example, usage of $f l u$ as a conditional tool for light-induced ${ }^{1} \mathrm{O}_{2}$ accumulation showed that one of the first sites of damage is the grana margin, which is protected by the SAFEGUARD1 protein (Wang et al., 2020a). Singlet oxygen is also quenched by carotenoids, tocopherols, and plastoquinones at thylakoid membranes close to its production site; where the excess energy of ${ }^{1} \mathrm{O}_{2}$ is normally absorbed by these molecules to avoid lipid peroxidation and photoinhibition (Krieger-Liszkay and Trebst, 2006; Ramel et al., 2012). Ubiquinol, ascorbate, and glutathione are also known to contribute to ${ }^{1} \mathrm{O}_{2}$ quenching (Laloi and Havaux, 2015).

Within the chloroplastic ETC, electrons can "leak" toward oxygen, thereby generating $\mathrm{O}_{2}{ }^{-}$- (Roach and Krieger-Liszkay, 2014). Most of this electron leakage occurs at the level of PSI, where ferredoxin conducts electrons toward $\mathrm{O}_{2}$ instead of $\mathrm{NADP}^{+}$, a process known as the Mehler reaction. This electron leak could be beneficial during $\mathrm{CO}_{2}$-limiting conditions, particularly during environmental stresses, because it provides an alternative sink to sustain electron flow of photosynthesis (Ort and Baker, 2002; Sun et al., 2020). In algae and cyanobacteria, the Mehler reaction functions as an important electron sink involving 10 to $50 \%$ of the photosynthetic electron flux (Badger et al., 2000). However, in higher plants, especially in angiosperms, the Mehler reaction rate is limited from negligibly small to less than $10 \%$ of the linear electron flow (Shirao et al., 2013; Mullineaux et al., 2018). $\mathrm{O}_{2}{ }^{*}$ is rapidly neutralized by SODs to the less toxic species $\mathrm{H}_{2} \mathrm{O}_{2}$ (Fig. 1).

In the chloroplasts, iron ( $\mathrm{Fe}) \mathrm{SODs}$ and the membrane-bound-copper/zinc $(\mathrm{Cu} / \mathrm{Zn}) \mathrm{SODs}$ are responsible for the conversion of $\mathrm{O}_{2} \cdot{ }^{-}$to $\mathrm{H}_{2} \mathrm{O}_{2}$ (Alscher et al., 2002; Pilon et al., 2011), which is subsequently reduced to water by ascorbate and thiol peroxidases. Of the nine ascorbate peroxidases (APXs) in Arabidopsis that use ascorbate as an electron donor to reduce $\mathrm{H}_{2} \mathrm{O}_{2}$ to $\mathrm{H}_{2} \mathrm{O}$, two localize to the chloroplasts [see review by Maruta et al. (2016) for detailed 
193

194

195

196

197

198

199

200

201

202

203

204

205

206

207

208

209

210

211

212

213

214

215

216

217

218

219

220

221

222

223

224

225

226

information on chloroplastic APXs]. The thylakoid (t)APX isoform serves as a first-line detoxification system to remove $\mathrm{H}_{2} \mathrm{O}_{2}$ produced at PSI (Fig. 1). In addition, $\mathrm{H}_{2} \mathrm{O}_{2}$ diffusing throughout the stroma is scavenged by stromal (s)APX (Asada, 2000). Interestingly, although transgenic overexpression of these chloroplastic APXs promote stress resistance in plants (Yabuta et al., 2002), loss-of-function mutants do not display any severe phenotypes under laboratory settings (Giacomelli et al., 2007; Kangasjärvi et al., 2008; Maruta et al., 2010; Caverzan et al., 2014), highlighting the several layers of partially redundant ROS detoxification mechanisms in chloroplasts. For example, in addition to the glutathioneascorbate cycle (Foyer and Halliwell, 1976; Asada, 2006), thiol peroxidases assist in the detoxification of chloroplastic $\mathrm{H}_{2} \mathrm{O}_{2}$. The chloroplasts also possess multiple thioredoxin types, including TRXm, TRXf, TRXx, TRXy, TRXz, and NADPH-dependent TRX reductase C (NTRC), several of which are essential for ROS metabolism (Buchanan, 2016; Nikkanen and Rintamäki, 2019).

\section{Mitochondrial ROS metabolism}

Similar to chloroplasts, the mitochondrial (m)ETC generates ROS. During respiration, $1 \%$ of the oxygen consumption has been estimated to generate $\mathrm{H}_{2} \mathrm{O}_{2}$ in plants (Puntarulo et al., 1988). Superoxide radicals can be formed at complex I and complex III of mETC, when oxygen is only reduced by a single electron (Fig. 1). Superoxides are produced in the flavoprotein region of NADH dehydrogenase (complex 1) in the mitochondrial matrix (Møller, 2001). At the complex III level, fully reduced ubiquinone $\left(\mathrm{QH}_{2}\right)$ passes electrons to cytochrome $c$, leaving an unstable ubisemiquinone radical that favors $\mathrm{O}_{2}$ as an electron acceptor, thus forming $\mathrm{O}_{2}{ }^{-*}$ radicals in both the matrix and in the intermembrane space. Enzymes in the matrix could also contribute to superoxide and $\mathrm{H}_{2} \mathrm{O}_{2}$ production, either at their flavin site (such as 2-oxoacid dehydrogenase complexes) or at their quinone-binding site (such as mitochondrial 3-phosphate dehydrogenase) [reviewed in Larosa and Remacle (2018)]. In the matrix, $\mathrm{O}_{2}{ }^{--}$is rapidly neutralized to $\mathrm{H}_{2} \mathrm{O}_{2}$ by MnSOD and, hence, $\mathrm{O}_{2}{ }^{-}$levels in the matrix are probably relatively low. However, it is unclear how $\mathrm{O}_{2}{ }^{-}$- is detoxified within the intermembrane space in plants. In yeast (Field et al., 2003) and mammals (Iñarrea et al., 2005), $\mathrm{Cu} / \mathrm{ZnSOD}$ has been shown to localize to the intermembrane space to detoxify $\mathrm{O}_{2}{ }^{\circ}$.

Given the evolutionarily conserved antioxidant machinery in mitochondria, a $\mathrm{Cu} / \mathrm{ZnSOD}$ might play similar role in plants as well. In addition, $\mathrm{O}_{2}{ }^{*-}$ might be scavenged by ascorbate (Halliwell and Foyer, 1976; Smirnoff, 2018), which is synthesized in the intermembrane 
space (Bartoli et al., 2000). Both $\mathrm{O}_{2}{ }^{\circ-}$ and its dismutation product $\mathrm{H}_{2} \mathrm{O}_{2}$ have been proposed to diffuse out to the cytosol, where they are subsequently detoxified or act as signaling molecules by altering local cytosolic redox states (Waszczak et al., 2018). Besides the main mETC components, other enzymes also feed electrons to the mETC. Galactono- $\gamma$-lactone dehydrogenase $(\mathrm{GLDH})$, in addition to its role in the structural regulation of the mETC complex I (Schimmeyer et al., 2016; Soufari et al., 2020), also catalyzes the last ascorbate biosynthesis step that provides an electron to cytochrome $c$ (Bartoli et al., 2000), as such contributing to an overreduction of the ubiquinone pool and, hence, increasing the mitochondrial ROS levels.

Mitochondrial $\mathrm{H}_{2} \mathrm{O}_{2}$ is neutralized to $\mathrm{H}_{2} \mathrm{O}$ by thiol and APXs, as well as by associated cycles similar to those in chloroplasts (Fig. 1). In fact, mitochondria and chloroplasts share most of the $\mathrm{H}_{2} \mathrm{O}_{2}$-scavenging enzymes, including APX, glutathione peroxidase (GPX), peroxiredoxin (PRX) II, monodehydroascorbate reductase (MDHAR), and glutathione reductase (Creissen et al., 1995; Chew et al., 2003; Rouhier et al., 2005; Navrot et al., 2006). In Arabidopsis, the stromal APX is dually targeted to chloroplasts and to the inner membrane facing the intermembrane space of mitochondria (Chew et al., 2003), suggesting that $\mathrm{H}_{2} \mathrm{O}_{2}$ as well as the APX activity-formed monodehydroascorbate must migrate through the membrane, because the other enzymes of the ascorbate-glutathione cycle are located in the matrix (Edwards et al., 1990; Creissen et al., 1995; Jimenez et al., 1997). In tomato (Solanum lycopersicum), however, APX isoforms have been detected both in the intermembrane space as well as in the matrix (Mittova et al., 2004). Although the exact suborganellar localization has not completely been elucidated in plants yet, it is evident that an ascorbate-glutathione cycle is present in the mitochondria (Møller, 2001; Chew et al., 2003). In contrast to chloroplasts, only GPX and PRXII, but not PRXQ nor 2-Cys PRX, occur in mitochondria. Mitochondria also possess an NADP/Trx system which is governed by Trx-o1, Trx-o2, and NTRA, the latter obtaining electrons from NADPH (Laloi et al., 2001; Meyer et al., 2012). Additional pathways are found in the mitochondria for the indirect regulation of ROS levels. The mETC in plants is highly branched and extra "alternative oxidoreductases" contribute to the electron flow, without producing energy (Fig. 1) (Møller, 2001; Rasmusson et al., 2008; Schertl and Braun, 2014). These alternative paths for electron transport allow plants to adjust their metabolism as required (Rasmusson et al., 2008). Type II NAD(P)H dehydrogenases (NDs) introduce electrons to the ubiquinone pool, thereby by-passing complex I, and are located both on the inner $\left(\mathrm{ND}_{\text {in }}\right)$ and external $\left(\mathrm{ND}_{\mathrm{ex}}\right)$ sides of the inner membrane. Because NDs have a relatively low affinity for $\mathrm{NAD}(\mathrm{P}) \mathrm{H}$ compared to complex I, 
they are believed to act only during NADH excess (Møller et al., 1993). However, because they can oxidize $\mathrm{NAD}(\mathrm{P}) \mathrm{H}$ originating from either the mitochondrial matrix or from the cytosol (diffused to the intermembrane space), they play a role in redox homeostasis and signaling, particularly during stress (Rasmusson et al., 2008; Podgórska et al., 2018). In Chlamydomonas, the $\mathrm{ND}_{\text {in }}$ has been characterized: no phenotype is detected when it is inactivated, but when the mutation is combined with a complex I mutation, the phenotype is much more severe than that of a single complex I mutant, suggesting that $\mathrm{Nd}_{\text {in }}$ also contributes to the NADH recycling for redox balance in the absence of stress conditions (Lecler et al., 2012). Another alternative path, the alternative oxidase (AOX), bypasses complex III and VI by transferring electrons from the ubiquinone pool to $\mathrm{O}_{2}$, thus preventing overreduction of the ubiquinone pool and ROS production (Umbach et al., 2005). Mutant studies have demonstrated that AOX inhibition of ROS formation is especially important during environmental stress, even when the mETC might not be the primary target of the stress (Umbach et al., 2005; Giraud et al., 2008; Wang et al., 2011; Yoshida et al., 2011; Vishwakarma et al., 2015). The AOX pathway helps to maintain photorespiration in mitochondria by ensuring continuous consumption of NADH generated from the conversion of glycine to serine by complex I, thus, contributing to PSII photoprotection in plants (Zhang et al., 2017), and is beneficial in maintaining both mitochondrial and chloroplastic functions during drought stress (Dahal and Vanlerberghe, 2017).

\section{Peroxisomal ROS metabolism}

Peroxisomes house several metabolic processes, which directly produce ROS, among which the main is the peroxisomal module of photorespiration (Fig. 1). As mentioned above, photorespiration is the process that converts $2 \mathrm{PG}$, produced by the oxygenase activity of Rubisco, to 3PGA, the product of the carboxylase activity of Rubisco. This process extends over three organelles via multiple intermediate compounds, with the first step in the peroxisomes that generates $\mathrm{H}_{2} \mathrm{O}_{2}$ through the glycolate oxidase (GOX) activity. Under nonstressed conditions, approximately $25 \%$ of the Rubisco activity results in photorespiration and thereby $\mathrm{H}_{2} \mathrm{O}_{2}$ production, but highly increases under $\mathrm{CO}_{2}$-limiting conditions, for example, after stomata closure during stress. Mutants with perturbed photorespiratory pathways display accelerated photoinhibition phenotypes under excess light conditions, 
suggesting an important role for photorespiration in preventing photoinhibition under $\mathrm{CO}_{2}-$ limiting conditions (Wingler et al., 2000; Takahashi and Badger, 2011).

Besides GOXs, other enzymes also catalyze reactions that result in $\mathrm{H}_{2} \mathrm{O}_{2}$ formation in peroxisomes (Fig. 1). In the first $\beta$-oxidation step that degrades fatty acids into acetyl-CoA, $\mathrm{H}_{2} \mathrm{O}_{2}$ is generated through Acyl-CoA oxidases. In sulfur metabolism, the conversion of sulfite to sulfate by sulfite oxidase also results in the production of $\mathrm{H}_{2} \mathrm{O}_{2}$. Normally, $\mathrm{H}_{2} \mathrm{O}_{2}$ is rapidly converted to water by catalase (see below), but under conditions of high sulfite levels, catalase is inhibited and the produced $\mathrm{H}_{2} \mathrm{O}_{2}$ assists in the sulfite detoxification by oxidizing sulfite to sulfate (Hänsch et al., 2006). Two purine metabolism enzymes, xanthine oxidoreductase (XOD) and urate oxidase, are additional ROS sources. XOD can function as either a xanthine oxidase or as a xanthine dehydrogenase, producing either $\mathrm{O}_{2}{ }^{-}{ }^{-}$or $\mathrm{H}_{2} \mathrm{O}_{2}$, respectively. However, until now, the presence of this enzyme in plant peroxisomes has only been confirmed in watermelon (Citrullus lanatus), castor bean (Ricinus communis), and pea (Pisum sativum) (Sandalio et al., 1988; del Río and Donaldson, 1995; Corpas et al., 2008). In other plants, such as Arabidopsis, only a cytosolic xanthine dehydrogenase isoform has been described (Corpas et al., 2008; Zarepour et al., 2010). Polyamine catabolism by FADdependent polyamine oxidases (PAOs) and copper-containing amine oxidases CuAOs also contributes to $\mathrm{H}_{2} \mathrm{O}_{2}$ production in peroxisomes, the cytosol, and apoplast [see reviews by Corpas et al. (2019); Wang et al. (2019)].

In pea, castor bean, and potato (Solanum tuberosum) tuber peroxisomes, a second source of $\mathrm{O}_{2}{ }^{-\cdots}$ is provided by the small ETC (del Río et al., 2002; del Río and López-Huertas, 2016). Although the small ETC is embedded in the peroxisomal membrane, ROS are generated outside the membrane. In pea, three peroxisomal membrane polypeptides (PMPs) are responsible for $\mathrm{O}_{2}{ }^{*-}$ production (López-Huertas et al., 1999). Two PMPs (MPM18 and MPM 32) use NADH as electron donor, whereas the other (PMP29) uses NADPH. Therefore, this small ETC is believed to be involved in the regeneration of $\mathrm{NAD}^{+}$and $\mathrm{NADP}^{+}$to sustain peroxisomal metabolism (del Río et al., 2002). PMP29 displays cytochrome $c$ reductase activity and is the main $\mathrm{O}_{2}{ }^{*}$ source. PMP18 and PMP32 are recognized as cytochrome $b$ and MDHAR, respectively (López-Huertas et al., 1999).

Peroxisomal $\mathrm{H}_{2} \mathrm{O}_{2}$ is mainly removed by catalase (Fig. 1), but peroxisomal PRX, APX, and the associated ascorbate-glutathione cycle also assist in the $\mathrm{H}_{2} \mathrm{O}_{2}$ removal. However, catalase is considered the dominant enzyme in $\mathrm{H}_{2} \mathrm{O}_{2}$ removal in peroxisomes, based on the severe stress-sensitive phenotypes in catalase-deficient plants (Mhamdi et al., 2010) that are not observed in peroxisomal APX-deficient plants (Narendra et al., 2006). The high 
abundance of catalase in peroxisomes and the nonspecific action of reductants, such as ascorbate or glutathione, might explain why catalase is more effective in peroxisomal $\mathrm{H}_{2} \mathrm{O}_{2}$ detoxification, despite its lower affinity for $\mathrm{H}_{2} \mathrm{O}_{2}$. For the dismutation of $\mathrm{O}_{2}{ }^{\cdot-}$ to $\mathrm{H}_{2} \mathrm{O}_{2}$, varying numbers and types of SOD isoforms in peroxisomes are in place (Nyathi and Baker, 2006). For example, whereas peroxisomes of watermelon possess both $\mathrm{Cu} / \mathrm{ZnSOD}$ and MnSOD, Arabidopsis and sunflower (Helianthus annuus) peroxisomes possess only a $\mathrm{Cu} / \mathrm{ZnSOD}$ (Bueno et al., 1995; Corpas et al., 1998; Rodríguez-Serrano et al., 2007; Huang et al., 2012).

\section{Apoplastic ROS production}

In contrast to the organellar ROS production, which occurs due to the nature of their resident metabolic pathways, in the apoplast ROS is produced in plants for growth, stomatal closure, and intercellular stress signaling [see reviews by Baxter et al. (2014); Podgórska et al. (2017); Chapman et al. (2019); Chen and Yang (2020)]. NADPH oxidases (respiratory burst oxidase homologs, RBOHs) are embedded in the plasma membrane and they transfer electrons from the cytoplasmic NADPH to the apoplastic oxygen, forming $\mathrm{O}_{2}{ }^{-}{ }^{-}$(Fig. 1). Of the ten $\mathrm{RBOH}$ proteins in Arabidopsis, ROS production by RBOHD and RBOHF have been shown to be especially important for different processes in leaves, including rapid systemic signaling in response to environmental stresses (Miller et al., 2009; Zandalinas et al., 2020), plantpathogen responses (Torres et al., 2002; Morales et al., 2016), and stomatal closure (Sierla et $a l ., 2016)$. RBOH activity is posttranslationally regulated by several mechanisms including calcium binding at its EF hand motif, N-terminal phosphorylation by a plethora of kinases including receptor-like cytoplasmic kinases such as Botrytis-Induced Kinase 1 (BIK1) (Kadota et al., 2014) and calcium-dependent protein kinases (Dubiella et al., 2013), and Cterminal phosphorylation by plasma-membrane bound receptor-like kinases (Kimura et al., 2020). The superoxide radicals produced by RBOHs are subsequently dismutated to $\mathrm{H}_{2} \mathrm{O}_{2}$ spontaneously or by an apoplastic SOD. Although the presence of this apoplastic SOD has been proposed based on biochemical assays of apoplast extracts, the genetic identity of this SOD is still unclear (Waszczak et al., 2018).

In addition to their presence in peroxisomes, PAOs are also localized to the apoplast and thus provide another means for $\mathrm{H}_{2} \mathrm{O}_{2}$ production in this compartment (Fig. 1). They are responsible for the catabolism of polyamines, such as spermidine and spermine, which simultaneously generate $\mathrm{H}_{2} \mathrm{O}_{2}$. Interestingly, NADPH oxidases and PAOs form a feedforward loop to increase ROS levels upon stresses (Gémes et al., 2016). Because the apoplast 
requires ROS for cell wall loosening and hence growth, the apoplast has evolved to remain in an oxidized state and entails only a limited antioxidant capacity (Müller et al., 2009; Noctor and Foyer, 2016). Indeed, in contrast to other organelles, in which peroxidases play an important role in the $\mathrm{H}_{2} \mathrm{O}_{2}$ detoxification, peroxidases in the apoplast perform the reverse reaction and are responsible for $\mathrm{H}_{2} \mathrm{O}_{2}$ and, subsequently $\mathrm{OH}^{*}$ formation (Passardi et al., 2005; Daudi et al., 2012). These additional sources of apoplastic ROS are likely to contribute to the same processes that require $\mathrm{RBOH}$-derived ROS, such as the regulation of stomatal closure (Sierla et al., 2016).

\section{$\mathrm{H}_{2} \mathrm{O}_{2}$ diffusion to the cytosol and nucleus}

Cytosolic $\mathrm{H}_{2} \mathrm{O}_{2}$ originates from the apoplast and the organelles. Although $\mathrm{H}_{2} \mathrm{O}_{2}$ can diffuse through the membrane, the lipid bilayer forms a poorly permeable barrier (Bienert et al., 2006). Mutant and heterologous expression studies demonstrated that plasma membrane aquaporins can be activated by kinases to assist in the transport of apoplastic $\mathrm{H}_{2} \mathrm{O}_{2}$ to the cytosol (Grondin et al., 2015; Rodrigues et al., 2017). A similar mechanism has been proposed for chloroplastic $\mathrm{H}_{2} \mathrm{O}_{2}$ based on chemical inhibition of aquaporins on isolated chloroplasts, although genetic evidence is still lacking (Borisova et al., 2012) (Fig. 1). When $\mathrm{H}_{2} \mathrm{O}_{2}$ reaches the cytosol, it is rapidly neutralized by APXs and GPXs (Borisova et al., 2012; Gaber et al., 2012), which are subsequently reduced through the ascorbate-glutathione cycle and thioredoxin/Trx reductase cycle (Mittler et al., 2004; Tripathy and Oelmüller, 2012). Because of its efficient antioxidant capacity, the cytosol has often been perceived as a "buffering zone" that limits intracellular $\mathrm{H}_{2} \mathrm{O}_{2}$ movements. Nevertheless, recent studies using the $\mathrm{H}_{2} \mathrm{O}_{2}$ fluorescent protein sensor roGFP2-Orp1 show that some stimuli, such as pathogen elicitors and the signaling molecule $\mathrm{H}_{2} \mathrm{~S}$, induce significant $\mathrm{RBOH}$-derived $\mathrm{H}_{2} \mathrm{O}_{2}$ accumulation in the cytosol (Scuffi et al., 2018; Nietzel et al., 2019).

ROS production has also been detected in the nucleus. The first evidence to suggest that ROS are actively produced in the plant nucleus was provided by experiments with isolated nuclei in which increased $\mathrm{H}_{2} \mathrm{O}_{2}$ levels were measured upon treatment with calcium (Ashtamker et al., 2007). Later, cryptochromes were proposed as a ROS source in plant nuclei (Consentino et al., 2015; Jourdan et al., 2015) because of a differential accumulation of nuclear ROS in overexpression and loss-of-function Arabidopsis mutants of cytochrome 1 (CRY1) and CRY2 (El-Esawi et al., 2017). Nonetheless, the physiological relevance or roles of this ROS source remain to be demonstrated in wild type plants and the molecular 
mechanisms behind the cryptochrome-mediated photoresponses are still being debated (Arthaut et al., 2017; Wang and Lin, 2020). Whereas no nuclear aquaporin has been described in plants, nuclear $\mathrm{H}_{2} \mathrm{O}_{2}$ can also accumulate through diffusion, presumably via the large nuclear pores. Nuclear $\mathrm{H}_{2} \mathrm{O}_{2}$ can originate from either the cytosol or from the organelles directly. $\mathrm{H}_{2} \mathrm{O}_{2}$ transfer from organelles can be facilitated through the physical association of the organelles to the nucleus (Exposito-Rodriguez et al., 2017). Organelles can also form extensions in the form of liquid tubules that could associate with the nucleus, called stromules (chloroplasts), matrixules (mitochondria), and peroxules (peroxisomes) (Noctor and Foyer, 2016). However, experimental evidence is only available for $\mathrm{H}_{2} \mathrm{O}_{2}$ transport via stromules into nuclei (Caplan et al., 2015) (Fig. 1).

Control of nuclear redox state is important for plant function. For example, in root cells of glutathione biosynthesis-deficient plants, the more oxidized redox state of their nuclei is accompanied by cell cycle arrest (Schnaubelt et al., 2015). In addition to redox buffers, nuclear $\mathrm{H}_{2} \mathrm{O}_{2}$ is also enzymatically regulated. Whereas none of the $\mathrm{H}_{2} \mathrm{O}_{2}$ detoxification enzymes discussed above (e.g. catalase, APX, etc.) are localized to the plant nucleus endogenously (Martins et al., 2018), $\mathrm{H}_{2} \mathrm{O}_{2}$ in the seed nucleus is neutralized by 1-Cys peroxiredoxins (Pulido et al., 2009), which is recycled via the Trx/Trx reductase cycle. In Arabidopsis, four Trx and eight Grx have been assigned a nuclear localization, although they are often associated with the cytosol as well (Delorme-Hinoux et al., 2016). Interestingly, their subcellular location can depend on environmental conditions. For example, GRXS17 resides in the cytosol under standard conditions, but accumulates in the nucleus upon heat treatment (Wu et al., 2012).

\section{ROS metabolism across organelles: some take-home messages}

When considering current knowledge on ROS production and processing in the different organelles, some generalised principles are apparent. First, metabolic perturbation leading to electron leakage toward molecular oxygen (both enzymatic and non-enzymatically) represent a shared mechanism for ROS production in chloroplasts, mitochondria and peroxisomes.

These organelles coincidentally contribute to the bulk of ROS accumulation in plant cells during abiotic stress. Second, the different organelles utilize similar ROS detoxification strategies entailing ROS-quenching metabolites and multi-gene enzyme families. Intriguingly, organelle-specific differences remain in the types of enzyme(s) and metabolite(s) involved in both the production and detoxification of different ROS. Whether these differences are the 
result of specializations due to the unique biochemical environment of each organelles, or are simply outcomes of random gene evolution, would be interesting to explore. Further insights could come from systematically studying the conservation and/or diversification of these organellar ROS metabolism across the evolutionary lineages.

In contrast to the organelles mentioned above, ROS production at the apoplast is initiated and controlled by the cell for stress responses rather than as consequences of metabolic perturbations (Kimura et al., 2020; Zandalinas et al., 2020). This difference between the apoplast and other organelles sets the scene of the dual nature of ROS as both harmful and useful metabolites, depending on their subcellular and metabolic context (Mittler, 2017). Collectively, these observations hint at the complex nature of evolution and specialization of ROS metabolism in plant cells.

\section{ROS-induced organellar signaling}

ROS accumulation is tuned to environmental stimuli that induce large-scale cellular responses, including transcriptomic reprogramming and metabolic adjustments. Different types and organellar origins of ROS can trigger specific nuclear transcriptomic responses as shown by genetic analysis of individual signaling pathways (De Clercq et al., 2013; Dogra et $a l ., 2017)$ as well as meta-analysis of transcriptome data from wild type and mutant plants exposed to exogenous ROS or ROS-inducing treatments (Willems et al., 2016). For example, PSII-derived ${ }^{1} \mathrm{O}_{2}$ induces a distinct subset of nuclear genes involved in the regulation of cell death, jasmonic acid signaling and PSII repair collectively termed Singlet Oxygen Responsive Genes [SORGs; (Chan et al., 2016b)]; with two different ${ }^{1} \mathrm{O}_{2}-$ responsive signaling pathways responsible for regulation of different SORG subsets depending on the severity of the imposed stress [further discussed below; (Kim et al., 2012; Ramel et al., 2012; Dogra et al., 2017)]. Another class of nuclear genes termed Plastid Redox Associated Nuclear Genes (PRANGs) comprise of various stress-associated genes including antioxidant enzymes and respond primarily to $\mathrm{PSI} \mathrm{H}_{2} \mathrm{O}_{2}$-associated signaling (Chan et al., 2016b). Similarly, mitochondrial ROS-inducing treatments induce a distinct class of genes termed Mitochondrial Dysfunction Stimulon (MDS) genes whose functions include mitochondrial ROS homeostasis (De Clercq et al., 2013). Yet, organellar ROS responses are not limited to the organelle in which ROS are generated: as further discussed below, chloroplast ROS-associated signals can 
have far-ranging impacts including on cytosolic ROS detoxification, endoplasmic reticulum protein homeostasis, and cell death.

With most of the ROS production occurring in the organelles and barring the relatively longer-lived $\mathrm{H}_{2} \mathrm{O}_{2}$, their short half-lives preclude ROS from being direct stress signals that travel (long-distance) from their production sites to elicit stress-responsive gene expression induction in the nucleus. Although $\mathrm{H}_{2} \mathrm{O}_{2}$ can be transferred directly from the chloroplasts to the nucleus (Exposito-Rodriguez et al., 2017), this mechanism on its own does not confer sufficient specificity, because the organellar origin of the nuclear $\mathrm{H}_{2} \mathrm{O}_{2}$ cannot be distinguished. Yet, the nuclear transcriptomic responses to peroxisomal and chloroplastic $\mathrm{H}_{2} \mathrm{O}_{2}$ are clearly distinct (Sewelam et al., 2014), indicating organelle-specific ROS-induced signaling pathways and/or ROS-independent mechanisms. In the past decades, several signaling pathways emanating from organelles have been shown to be crucial for the adjustment and/or repair of the organelles during environmental stress. These pathways are termed organellar "operational control" retrograde signaling [first described by Pogson et al. (2008); reviewed in Dietz et al. (2016); Leister (2017)]. These signaling pathways share the common trait of being responsive to, or associated with, ROS.

\section{Chloroplastic ROS-induced retrograde signaling}

As described above, ${ }^{1} \mathrm{O}_{2}$ is commonly produced at PSII and quenched by pigments, including $\beta$-carotene bound to the reaction centers of photosystems embedded in the thylakoid membrane. $\beta$-carotene itself is oxidized by ${ }^{1} \mathrm{O}_{2}$, giving rise to various cleavage products including $\beta$-cyclocitral ( $\beta$-CC) and dihydroactinidiolide (Ramel et al., 2012), which act as chloroplast retrograde signals during excess light stress (Fig. 2). Upon production, $\beta$-CC can induce ${ }^{1} \mathrm{O}_{2}$-specific stress responses, such as the up-regulation of the glutathione transferase class tau 5 (GSTU5) and mitogen-activated protein kinase 18 (MAPKKK18) (Ramel et al., 2012). The $\beta$-CC signaling cascade proceeds at least partially via the RNA-binding protein methylene blue sensitivity 1 (MBS1) (Shumbe et al., 2017) and intersects with various stress pathways, such as the xenobiotic detoxification response (D'Alessandro et al., 2018) and the salicylic acid (SA) signaling (Lv et al., 2015) for photooxidative stress acclimation. Interestingly, $\beta$-CC rapidly dissolves into $\beta$-cyclocitric acid ( $\beta$-CCA), which only partially overlaps with the former in terms of regulated genes (Fig. 2), suggesting distinct functions for these two closely related metabolites (D'Alessandro et al., 2019). Although multiple 
downstream effectors of $\beta$-CC have been characterized, direct sensor(s)/receptor(s) of $\beta$-CC are yet to be identified.

Recently another ${ }^{1} \mathrm{O}_{2}$-specific stress sensor located on the thylakoid membrane of chloroplasts has been characterized, namely the EXECUTER 1 (EX1) protein (Wang et al., 2016; Dogra et al., 2019). EX1 is associated with PSII in the grana margin (Fig. 2) and can undergo a posttranslational modification (PTM) by ${ }^{1} \mathrm{O}_{2}$ at the Trp643 residue of its singlet oxygen sensor (SOS) domain. This PTM step is critical for initiating EX1 degradation by the thylakoid-membrane bound FtsH2 metalloprotease, in which the protease domain faces the stromal side of thylakoids (Kato and Sakamoto, 2009) for activation of downstream ${ }^{1} \mathrm{O}_{2}$ signaling (Dogra et al., 2017; Dogra et al., 2019). It is possible that the as yet-unidentified degradation product(s) of EX1 act(s) as a retrograde signal that triggers ${ }^{1} \mathrm{O}_{2}$-responsive gene activation in the nucleus, although experimental validation is still required. Although signals derived both from $\beta$-CC and EX1-FtsH2 are triggered by ${ }^{1} \mathrm{O}_{2}$, they originate from the grana core and margin, respectively. This spatial difference of ${ }^{1} \mathrm{O}_{2}$ generation may confer specificity in the cellular response, because $\beta$-CC and EX1 activate different sets of ${ }^{1} \mathrm{O}_{2}$-responsive genes in the nucleus with only a minimal overlap between the gene sets (Dogra et al., 2017). An alternative explanation is provided by the environmental context, since $\beta$-CC is associated with cell-death promoting under high light stress conditions while EX1-mediated signaling can occur at lower light intensities (Kim et al., 2012).

Methylerythritol cyclodiphosphate (MEcPP - also abbreviated as MEcDP in some literature) is another chloroplastic stress retrograde signal that accumulates during wounding and high-light stresses (Xiao et al., 2012). MEcPP is an intermediate metabolite of the methylerythritol phosphate (MEP) pathway for isoprenoid biosynthesis in plastids (Fig. 2). MEcPP accumulation is probably responsive to ROS, because the MEcPP-degrading enzyme 4-hydroxy-3-methylbut-2-enyl diphosphate synthase (HDS) contains a redox-sensitive ironsulfur cluster at its active site (Seemann et al., 2005) and bacterial HDS is known to be redox regulated (Ostrovsky et al., 1998). Extensive work on the hds mutant shows that MEcPP activates various stress pathways via the nuclear transcription factor CAMTA3, including plastidial radical scavenging and the endoplasmic reticulum (ER)-unfolded protein response (Benn et al., 2016). Over-accumulated MEcPP also impacts on growth-regulating pathways (de Souza et al., 2017; Wang et al., 2017; Jiang et al., 2018; Jiang et al., 2020). Intriguingly, quantification of MEcPP accumulation in isolated chloroplasts versus whole-leaf extracts of oxidatively stressed spinach (Spinacia oleracea) revealed that the bulk of the MEcPP remains in the chloroplasts (Rivasseau et al., 2009). If this predominantly chloroplast-localized 
accumulation of MEcPP were evolutionarily conserved across plants, it could suggest that either (i) low-abundance MEcPP in the cytosol is rapidly and sensitively sensed by highaffinity receptor(s), or (ii) MEcPP is actually perceived within chloroplasts and its information of chloroplast stress relayed to the nucleus by unknown component(s). Examining these hypothetical possibilities could provide novel insights into this pathway.

Drought and high light stresses both induce accumulation of the chloroplast retrograde signal 3'-phosphoadenosine-5'-phosphate (PAP) via oxidative inactivation of its catabolic enzyme SAL1 (Fig. 2) (Estavillo et al., 2011; Chan et al., 2016a). Interestingly, although PAP degradation by the redox-sensitive SAL1 may occur in both chloroplasts and mitochondria due to the dual localization of SAL1, PAP synthesis is thought to occur primarily in the cytosol and Golgi, based on the predicted localization of its biosynthetic enzymes, the sulfotransferases (SOTs). The SOTs transfer a sulfonyl group from 3'-phosphoadenosine-5'phosphosulfate (PAPS) to other acceptor molecules, such as desulfoglucosinolates, thereby releasing PAP as a by-product (Chan et al., 2019). The high polarity of PAP prevents it from crossing the organelle outer membrane by diffusion. Rather, PAP traverses the organellar membrane via two PAP transporters in Arabidopsis, namely the PAPS/PAP transporter 1 (PAPST1) that is localized to the plastid envelope membrane and thylakoids (Gigolashvili et al., 2012) and the PAPST2 in the plastidial and/or mitochondrial membranes in a tissuespecific manner (Ashykhmina et al., 2019). Both transporters are antiporters that can exchange any two of either PAPS, PAP, ATP or ADP across the organelle membrane. PAPSTs probably play crucial roles in regulating the PAP-mediated signaling, because the PAP biosynthesis sites are uncoupled from those of its degradation. How these transporters fit into the PAP signaling framework is not fully understood (Chan et al., 2019). The PAP movement from the cytosol into the nucleus is thought to proceed via passive diffusion (Estavillo et al., 2011). In the nucleus, PAP inhibits the activity of 5'-3' exoribonucleases (XRNs), which leads to altered RNA Polymerase II activity, thereby inducing the upregulation of many stress-responsive genes, including chloroplast- and cytosol-targeted APXs (Estavillo et al., 2011; Crisp et al., 2018). Interestingly, PAP also affects ROS metabolism at the apoplast of guard cells, most likely by influencing the activity of NADPH oxidases (Pornsiriwong et al., 2017).

Are there other ROS-responsive/dependent chloroplast signals, whether protein or metabolite-based? There is increasing evidence that some chloroplast-localized proteins can be directly translocated from the chloroplasts to the nucleus (Krupinska et al., 2020). In response to the tobacco mosaic virus effector protein p50, ROS accumulates in chloroplasts. 
562 Concurrently, the chloroplastic defense protein $\mathrm{N}$ receptor interacting protein 1 (NRIP1)

563 recognizes p50 and is translocated with p50 to the nucleus, possibly via stromules (Caplan et

$564 a l ., 2015)$. In another example, plants expressing a tagged version of the DNA-binding protein

565 WHIRLY1 specifically in the chloroplast genome, thus ruling out dual targeting of

566 cytosolically translated WHIRLY1, also show plastidial WHIRLY1 translocation to the

567 nucleus and coincided with the increased expression of pathogenesis-related genes, consistent

568 with their promoters as targets for WHIRLY1 binding. WHIRLY1 translocation has been

569 proposed to be regulated by changes in the chloroplast redox state, for example during

570 pathogen infection (Foyer et al., 2014) when ROS also overaccumulates (Caplan et al., 2015).

571 It will be important to fully elucidate the mechanism(s) by which ROS regulate the

572 translocation of these proteins, given their crucial roles.

573 Similarly to how ROS can react with $\beta$-carotene to produce electrophilic $\beta$-CC, ROS

574 can also react with phospholipids -key components of cellular and organellar membranes- to

575 form lipid peroxides and/or oxylipins (Farmer and Mueller, 2013; Mano et al., 2019). Lipid

576 peroxides contribute to a variety of reactive electrophile species (RES) or reactive carbonyl

577 species (RCS) that can further react with proteins and covalently modify them (Winger et al.,

578 2005; Winger et al., 2007). Lipid peroxides and their derivatives can trigger various

579 physiological responses in plants and algae, including alteration in redox homeostasis,

580 activation of programmed cell death, and changes in gene expression in the nucleus (Biswas

581 and Mano, 2015; Roach et al., 2018). Interestingly, treatment of plants and/or algae with

582 moderate level of oxylipins/RES/RCS improved their tolerance toward stresses (e.g., light and

583 heat) (Roach et al., 2018; Monte et al., 2020). Consequently, there is an increasing appraisal

584 for oxylipins/RES/RCS to be considered also as players in ROS/organelle retrograde

585 signaling; although conclusive evidence is still required (Farmer and Mueller, 2013; Alché,

586 2019; Mano et al., 2019; Muñoz and Munné-Bosch, 2020).

587

588

Mitochondrial ROS-induced signaling

589

590 In contrast to chloroplast ROS-induced signaling pathways, which are rather well

591 characterized to a certain extent, detailed knowledge on equivalent mitochondrial pathways

592 remain sparse. Only one major pathway has been elucidated to date, involving the

593 Arabidopsis NAC domain-containing protein 13 (ANAC013) (De Clercq et al., 2013),

594 ANAC017 (Ng et al., 2013; Meng et al., 2019), and radical-induced cell death 1 (RCD1) 
595 (Shapiguzov et al., 2019). Perturbations of the mETC leads to translocation of the ERtethered ANAC013 and ANAC017 transcription factors to the nucleus via the action of unidentified proteases (Fig. 2). In the nucleus, ANAC013 and ANAC017 regulate the expression of mitochondrial dysfunction stimulon (MDS) genes, which encode, among others, AOXIa that is crucial for mitochondrial ROS detoxification [reviewed in Waszczak et al. (2018); Dourmap et al. (2020); Mielecki et al. (2020); Wang et al. (2020b)]. RCD1 is a redox-sensitive WWE domain-containing nuclear protein. Under unstressed conditions, monomeric RCD1 physically interacts with and sequesters ANAC013/ANAC017. Under stress, ROS-induced oligomerization of RCD1 releases this inhibition, allowing ANAC013/ANAC017 to regulate the MDS gene expression (Shapiguzov et al., 2019). Interestingly, RCD1-ANAC013/017 were proposed to intersect with SAL1-PAPmediated chloroplast retrograde signaling based on similarities in MDS gene expression and oxidative stress phenotypes of the respective mutants (Van Aken and Pogson, 2017; Shapiguzov et al., 2019). Although the exact molecular mechanism behind this interaction remains a mystery, these findings suggest that chloroplast and mitochondrial retrograde signaling converge in the nucleus (Wang et al., 2020b). One possible purpose of such convergence may be the coordination of transcriptional changes to fine-tune the overall cellular energy metabolism by readjusting the capacity of both organelles according to environmental cues.

\section{Peroxisomal ROS-induced signaling}

The existence of peroxisome-derived retrograde signaling has been proposed previously (Foyer and Noctor, 2003). This hypothesis is plausible because peroxisomes are the sources of various important signaling molecules, including $\beta$-oxidation--derived molecules, such as some hormone (jasmonic acid, auxin, and SA) derivatives, ROS, reactive nitrogen species (RNS), and components of redox buffers that convey the change in the peroxisomal redox state (Baker et al., 2006; Nyathi and Baker, 2006). Peroxisomal ROS triggers specific transcriptional changes in the nucleus (Sewelam et al., 2014). Reported changes in the peroxisomes under oxidative stress include altered morphology (shape and size), mobility, and numbers (biogenesis vs pexophagy/turnover) (Wang et al., 2015; Jaipargas et al., 2016; Rodríguez-Serrano et al., 2016; Su et al., 2019; Pan et al., 2020; Sandalio et al., 2021). These features hint at the possibility of peroxisomal ROS signaling, leading to changes in the nuclear gene expression that readjust peroxisome properties for acclimation, corresponding 
629

630

631

632

633

634

635

636

637

638

639

640

641

642

643

644

645

646

647

648

649

650

651

652

653

654

655

656

657

658

659

660

with the definition of retrograde signaling (Chan et al., 2016b). However, no ROS-induced peroxisome-to-nucleus retrograde signaling pathway has been described to date (Fig. 2).

Whereas knowledge of peroxisomal ROS signaling is still fragmentary, in the past decade loss-of-function studies with the peroxisomal catalase 2 (cat2) mutant have revealed candidate pathways and components. Conditional overproduction of peroxisomal ROS and enhanced cell death in cat 2 are associated with altered glutathione redox state and activation of the hypersensitive response via SA (Queval et al., 2007; Chaouch et al., 2010). Forward and reverse genetic screens for suppressors of the cat2 photorespiratory ROS-related phenotypes also identified crucial roles for hormonal signaling and various transcription factors (Kaurilind et al., 2015; Kerchev et al., 2016; Waszczak et al., 2016). Interestingly the different processes mentioned above, albeit merely correlative, have also been linked with different chloroplast retrograde signaling pathways; for example, SA with $\beta$-CC signaling, auxin with both MEcPP and PAP, and glutathione redox state with PAP (Lv et al., 2015; Jiang et al., 2018; Phua et al., 2018). The biggest challenge remains to identify the actual peroxisomal retrograde signal(s), if they exist, and elucidate the pathways in which they function. As part of this process, a starting point could be to examine the extent to which peroxisomal ROS diffuses into the cytosol and nuclei to affect redox couples and/or signaling proteins directly.

\section{Perspectives}

In the past decade, although our understanding of ROS metabolism and signaling in different plant organelles has progressed, several questions remain. First, do the different retrograde signals function in concert with, independently of, or even antagonistically to each other? Second, how do these signals intersect with the nuclear $\mathrm{H}_{2} \mathrm{O}_{2}$ perception directly transferred from chloroplasts? To address this question, the direct impact of the chloroplast-to-nucleus $\mathrm{H}_{2} \mathrm{O}_{2}$ transfer on the nuclear transcriptome needs to be determined as well. Third, which are the genes encoding the missing components in the organellar ROS signaling, including potential ROS/redox sensors in mitochondria and peroxisomes? In the specific case of ANAC013/017-mediated mitochondrial signaling, an important related question is how is mitochondrial ROS perception transduced to the ER, where the ANAC proteins reside.

Fourth, are the different organelle ROS signaling networks interconnected in the same manner 
661

662

663

664

665

666

667

668

669

670

671

672

673

674

675

676

677

678

679

680

681

682

683

684

685

686

687

688

689

690

691

692

693

694

as the metabolic link between chloroplasts, mitochondria, and peroxisomes; and if so, which are the missing components?

Each of these questions could be partially addressed by identifying signaling proteins responsive to ROS from the different organelles. Recent technological advancements enabled in vivo trapping and identification of oxidized cysteines in different subcellular compartments upon oxidative stresses in cultured Arabidopsis cells (De Smet et al., 2019; Huang et al., 2019; Wei et al., 2020). These approaches revealed potentially crucial roles for ROSmediated cysteine oxidation in RNA processing and amino acid metabolism (De Smet et al., 2019; Huang et al., 2019) and provide a complementary strategy to the conventional biochemical characterization of signaling proteins identified from genetic screens (Lee et al., 2007; Estavillo et al., 2011; Chan et al., 2016a; Dogra et al., 2019). Nevertheless, a major technical challenge lies in the improvement of the sensitivity of such cysteine-trapping approaches to capture novel organellar retrograde redox sensors/signals. Transfer of the trapping technology from cultured cells to intact plants will also enhance the physiological relevance of any identified ROS sensor(s).

Another possible avenue for future breakthroughs in ROS signaling is to break down the complexity of the studied biological system. A plant leaf is composed of several highly specialized cell types that can have diverse ROS signaling pathways, as evidenced by the contribution of apoplastic ROS production specifically by vascular cells, but not other cell types, to systemic stress signaling (Zandalinas et al., 2020). It is noteworthy that transcriptomics of isolated single cells from a complex organ is now feasible for Arabidopsis (Wendrich et al., 2020). Complementary approaches such as using cultured Arabidopsis cells derived from a single tissue type (Van Leene et al., 2007) and/or shifting completely to a unicellular model organism that houses both chloroplasts and mitochondria, such as Chlamydomonas reinhardtii, could help identify missing ROS and organellar retrograde signaling pathways that are "diluted" by whole-leaf analyses. For instance, Shao et al. (2013) successfully utilized C. reinhardtii to detect new players in ROS signaling in Arabidopsis, but in other cases the identified proteins had been lost in higher plants (Fischer et al., 2012; Wakao et al., 2014). As homologous proteins for the Arabidopsis organellar signaling proteins SAL1, HDS1, and EX1 are conserved in C. reinhardtii, it may be interesting to assess the extent to which the principles and components of ROS signaling, studied extensively in Arabidopsis, are actually maintained across the green lineage. In that respect, mutants affected in NPQ represent interesting tools to understand the response to light stress and signaling from the chloroplast. The photosynthetic response of mutants affected in $\mathrm{qT}$ 
695 (lhcsr mutants), qE (stt7 mutants), or both pathways to various light conditions (high light or 696 fluctuating light) has been characterized in detail [e.g. Peers et al. (2009); Allorent et al.

697 (2013); Girolomoni et al. (2019)]. Although the retrograde signaling leading to changes in the 698 LHCSR3 expression has not been elucidated yet, the involvement of chloroplastic $\mathrm{Ca}^{2+}$ 699 variations and redox imbalance has been proposed [reviewed in Rea et al. (2018)]. In 700 addition, the availability of respiratory deficient mutants (Salinas et al., 2014), and the 701 existence of double mutants affected in both respiration and photosynthetic activity (Cardol et 702 al., 2009; Massoz et al., 2017; Larosa et al., 2018) could help decipher retrograde signaling 703 from mitochondria and its connection with the chloroplast.

704

705

\section{Acknowledgements}

706 The authors thank Dr. Martine De Cock for help in preparing the manuscript. This work was 707 supported by the Research Foundation-Flanders-Fonds de la Recherche Scientifique-FNRS 708 (Excellence of Science project no. 30829584 to C.R., and F.V.B.). S.Y.P is supported by the 709 EOS 30829584 funds. B.D.S. is indebted to the Agency for Innovation by Science and 710 Technology for a predoctoral fellowship (no. 141007) and K.X.C. to Research Foundation711 Flanders for a postdoctoral fellowship (no. 12N4818N).

712

\section{Conflict of interest}

714 The authors declare no conflict of interest. 


\section{References}

Alché JdD. 2019. A concise appraisal of lipid oxidation and lipoxidation in higher plants. Redox Biology 23, 101136.

Allorent G, Tokutsu R, Roach T, Peers G, Cardol P, Girard-Bascou J, Seigneurin-Berny D, Petroutsos D, Kuntz M, Breyton C, Franck F, Wollman F-A, Niyogi KK, KriegerLiszkay A, Minagawa J, Finazzi G. 2013. A Dual Strategy to Cope with High Light in Chlamydomonas reinhardtii. The Plant Cell 25, 545-557.

Alscher RG, Erturk N, Heath LS. 2002. Role of superoxide dismutases (SODs) in controlling oxidative stress in plants. Journal of Experimental Botany 53, 1331-1341.

Andersson B, Aro E-M. 2001. Photodamage and D1 Protein Turnover in Photosystem II. In: Aro E-M, Andersson B, eds. Regulation of Photosynthesis. Dordrecht: Springer Netherlands, 377-393.

Arthaut L-D, Jourdan N, Mteyrek A, Procopio M, El-Esawi M, d'Harlingue A, Bouchet P-E, Witczak J, Ritz T, Klarsfeld A, Birman S, Usselman RJ, Hoecker U, Martino CF, Ahmad M. 2017. Blue-light induced accumulation of reactive oxygen species is a consequence of the Drosophila cryptochrome photocycle. PLOS ONE 12, e0171836.

Asada K. 2000. The water-water cycle as alternative photon and electron sinks. Philosophical transactions of the Royal Society of London. Series B, Biological sciences 355, 1419-1431.

Asada K. 2006. Production and Scavenging of Reactive Oxygen Species in Chloroplasts and Their Functions. Plant physiology 141, 391-396.

Ashtamker C, Kiss V, Sagi M, Davydov O, Fluhr R. 2007. Diverse subcellular locations of cryptogein-induced reactive oxygen species production in tobacco Bright Yellow-2 cells. Plant physiology 143, 1817-1826.

\section{Ashykhmina N, Lorenz M, Frerigmann H, Koprivova A, Hofsetz E, Stührwohldt N,} Flügge U-I, Haferkamp I, Kopriva S, Gigolashvili T. 2019. PAPST2 Plays Critical Roles in Removing the Stress Signaling Molecule 3'-Phosphoadenosine 5'-Phosphate from the Cytosol and Its Subsequent Degradation in Plastids and Mitochondria. The Plant Cell 31, 231-249. 
Badger MR, von Caemmerer S, Ruuska S, Nakano H. 2000. Electron flow to oxygen in higher plants and algae: rates and control of direct photoreduction (Mehler reaction) and rubisco oxygenase. Philos Trans R Soc Lond B Biol Sci 355, 1433-1446.

Baker A, Graham IA, Holdsworth M, Smith SM, Theodoulou FL. 2006. Chewing the fat: beta-oxidation in signalling and development. Trends in Plant Science 11, 124-132.

Bartoli CG, Pastori GM, Foyer CH. 2000. Ascorbate Biosynthesis in Mitochondria Is Linked to the Electron Transport Chain between Complexes III and IV. Plant physiology 123, 335-344.

Baxter A, Mittler R, Suzuki N. 2014. ROS as key players in plant stress signalling. Journal of Experimental Botany 65, 1229-1240.

Benn G, Bjornson M, Ke H, De Souza A, Balmond EI, Shaw JT, Dehesh K. 2016.

Plastidial metabolite MEcPP induces a transcriptionally centered stress-response hub via the transcription factor CAMTA3. Proceedings of the National Academy of Sciences 113, 88558860.

Bielski BHJ, Allen AO. 1977. Mechanism of the disproportionation of superoxide radicals. The Journal of Physical Chemistry 81, 1048-1050.

Bienert GP, Schjoerring JK, Jahn TP. 2006. Membrane transport of hydrogen peroxide. Biochimica et Biophysica Acta (BBA) - Biomembranes 1758, 994-1003.

Biswas MS, Mano Ji. 2015. Lipid Peroxide-Derived Short-Chain Carbonyls Mediate Hydrogen Peroxide-Induced and Salt-Induced Programmed Cell Death in Plants. Plant physiology 168, 885-898.

Borisova MM, Kozuleva MA, Rudenko NN, Naydov IA, Klenina IB, Ivanov BN. 2012. Photosynthetic electron flow to oxygen and diffusion of hydrogen peroxide through the chloroplast envelope via aquaporins. Biochimica et Biophysica Acta (BBA) - Bioenergetics 1817, 1314-1321.

Buchanan BB. 2016. The Path to Thioredoxin and Redox Regulation in Chloroplasts. Annual Review of Plant Biology 67, 1-24. 
Bueno P, Varela J, Gimenez-Gallego G, del Rio LA. 1995. Peroxisomal Copper,Zinc Superoxide Dismutase (Characterization of the Isoenzyme from Watermelon Cotyledons). Plant physiology 108, 1151-1160.

Caplan Jeffrey L, Kumar Amutha S, Park E, Padmanabhan Meenu S, Hoban K, Modla S, Czymmek K, Dinesh-Kumar Savithramma P. 2015. Chloroplast Stromules Function during Innate Immunity. Developmental Cell 34, 45-57.

Cardol P, Alric J, Girard-Bascou J, Franck F, Wollman F-A, Finazzi G. 2009. Impaired respiration discloses the physiological significance of state transitions in Chlamydomonas. Proceedings of the National Academy of Sciences 106, 15979-15984.

Caverzan A, Bonifacio A, Carvalho FEL, Andrade CMB, Passaia G, Schünemann M, Maraschin FdS, Martins MO, Teixeira FK, Rauber R, Margis R, Silveira JAG, MargisPinheiro M. 2014. The knockdown of chloroplastic ascorbate peroxidases reveals its regulatory role in the photosynthesis and protection under photo-oxidative stress in rice. Plant Science 214, 74-87.

Chan KX, Mabbitt PD, Phua SY, Mueller JW, Nisar N, Gigolashvili T, Stroeher E, Grassl J, Arlt W, Estavillo GM, Jackson CJ, Pogson BJ. 2016a. Sensing and signaling of oxidative stress in chloroplasts by inactivation of the SAL1 phosphoadenosine phosphatase. Proceedings of the National Academy of Sciences 113, E4567-E4576.

Chan KX, Phua SY, Breusegem FV. 2019. Secondary sulfur metabolism in cellular signalling and oxidative stress responses. Journal of Experimental Botany 70, 4237-4250.

Chan KX, Phua SY, Crisp P, McQuinn R, Pogson BJ. 2016b. Learning the Languages of the Chloroplast: Retrograde Signaling and Beyond. Annual Review of Plant Biology 67, 2553.

Chaouch S, Queval G, Vanderauwera S, Mhamdi A, Vandorpe M, Langlois-Meurinne M, Van Breusegem F, Saindrenan P, Noctor G. 2010. Peroxisomal Hydrogen Peroxide Is Coupled to Biotic Defense Responses by ISOCHORISMATE SYNTHASE1 in a DaylengthRelated Manner. Plant physiology 153, 1692-1705. 
Chapman JM, Muhlemann JK, Gayomba SR, Muday GK. 2019. RBOH-Dependent ROS Synthesis and ROS Scavenging by Plant Specialized Metabolites To Modulate Plant Development and Stress Responses. Chemical research in toxicology 32, 370-396.

Chen Q, Yang G. 2020. Signal Function Studies of ROS, Especially RBOH-Dependent ROS, in Plant Growth, Development and Environmental Stress. Journal of Plant Growth Regulation 39, 157-171.

Chew O, Whelan J, Millar AH. 2003. Molecular definition of the ascorbate-glutathione cycle in Arabidopsis mitochondria reveals dual targeting of antioxidant defenses in plants. Journal of Biological Chemistry 278, 46869-46877.

Consentino L, Lambert S, Martino C, Jourdan N, Bouchet P-E, Witczak J, Castello P, El-Esawi M, Corbineau F, d'Harlingue A, Ahmad M. 2015. Blue-light dependent reactive oxygen species formation by Arabidopsis cryptochrome may define a novel evolutionarily conserved signaling mechanism. New Phytologist 206, 1450-1462.

Corpas FJ, del Río LA, Palma JM. 2019. Plant peroxisomes at the crossroad of NO and H2O2 metabolism. Journal of Integrative Plant Biology 61, 803-816.

Corpas FJ, Palma JM, Sandalio LM, Valderrama R, Barroso JB, del Río LA. 2008. Peroxisomal xanthine oxidoreductase: Characterization of the enzyme from pea (Pisum sativum L.) leaves. Journal of Plant Physiology 165, 1319-1330.

Corpas FJ, Sandalio LM, Del RÍO LA, Trelease RN. 1998. Copper-zinc superoxide dismutase is a constituent enzyme of the matrix of peroxisomes in the cotyledons of oilseed plants. New Phytologist 138, 307-314.

\section{Correa-Galvis V, Redekop P, Guan K, Griess A, Truong TB, Wakao S, Niyogi KK,} Jahns P. 2016. Photosystem II Subunit PsbS Is Involved in the Induction of LHCSR Proteindependent Energy Dissipation in Chlamydomonas reinhardtii. Journal of Biological Chemistry 291, 17478-17487.

Creissen G, Reynolds H, Xue Y, Mullineaux P. 1995. Simultaneous targeting of pea glutathione reductase and of a bacterial fusion protein to chloroplasts and mitochondria in transgenic tobacco. The Plant Journal 8, 167-175. 
Crisp PA, Smith AB, Ganguly DR, Murray KD, Eichten SR, Millar AA, Pogson BJ. 2018. RNA Polymerase II Read-Through Promotes Expression of Neighboring Genes in SAL1-PAP-XRN Retrograde Signaling. Plant physiology 178, 1614-1630.

D'Alessandro S, Mizokami Y, Légeret B, Havaux M. 2019. The Apocarotenoid $\beta$ Cyclocitric Acid Elicits Drought Tolerance in Plants. iScience 19, 461-473.

D’Alessandro S, Ksas B, Havaux M. 2018. Decoding $\beta$-Cyclocitral-Mediated Retrograde Signaling Reveals the Role of a Detoxification Response in Plant Tolerance to Photooxidative Stress. The Plant Cell 30, 2495-2511.

Dahal K, Vanlerberghe GC. 2017. Alternative oxidase respiration maintains both mitochondrial and chloroplast function during drought. New Phytologist 213, 560-571.

\section{Dall'Osto L, Holt NE, Kaligotla S, Fuciman M, Cazzaniga S, Carbonera D, Frank HA,} Alric J, Bassi R. 2012. Zeaxanthin protects plant photosynthesis by modulating chlorophyll triplet yield in specific light-harvesting antenna subunits. J Biol Chem 287, 41820-41834.

\section{Daudi A, Cheng Z, O’Brien JA, Mammarella N, Khan S, Ausubel FM, Bolwell GP.} 2012. The Apoplastic Oxidative Burst Peroxidase in Arabidopsis Is a Major Component of Pattern-Triggered Immunity. The Plant Cell 24, 275-287.

De Clercq I, Vermeirssen V, Van Aken O, Vandepoele K, Murcha MW, Law SR, Inzé A, Ng S, Ivanova A, Rombaut D, van de Cotte B, Jaspers P, Van de Peer Y, Kangasjärvi J, Whelan J, Van Breusegem F. 2013. The Membrane-Bound NAC Transcription Factor ANAC013 Functions in Mitochondrial Retrograde Regulation of the Oxidative Stress Response in Arabidopsis. The Plant Cell 25, 3472-3490.

De Smet B, Willems P, Fernandez-Fernandez AD, Alseekh S, Fernie AR, Messens J, Van Breusegem F. 2019. In vivo detection of protein cysteine sulfenylation in plastids. The Plant Journal 97, 765-778.

de Souza A, Wang J-Z, Dehesh K. 2017. Retrograde Signals: Integrators of Interorganellar Communication and Orchestrators of Plant Development. Annual Review of Plant Biology 68, 85-108. 
del Río LA, Corpas FJ, Sandalio LM, Palma JM, Gómez M, Barroso JB. 2002. Reactive oxygen species, antioxidant systems and nitric oxide in peroxisomes. Journal of Experimental Botany 53, 1255-1272.

del Río LA, Donaldson RP. 1995. Production of Superoxide Radicals in Glyoxysomal Membranes from Castor Bean Endosperm. Journal of Plant Physiology 146, 283-287.

del Río LA, López-Huertas E. 2016. ROS Generation in Peroxisomes and its Role in Cell Signaling. Plant and Cell Physiology 57, 1364-1376.

Delorme-Hinoux V, Bangash SA, Meyer AJ, Reichheld JP. 2016. Nuclear thiol redox systems in plants. Plant Sci 243, 84-95.

Dietz K-J. 2015. Efficient high light acclimation involves rapid processes at multiple mechanistic levels. Journal of Experimental Botany 66, 2401-2414.

Dietz K-J, Turkan I, Krieger-Liszkay A. 2016. Redox- and Reactive Oxygen SpeciesDependent Signaling into and out of the Photosynthesizing Chloroplast. Plant physiology 171, 1541-1550.

Dogra V, Duan J, Lee KP, Lv S, Liu R, Kim C. 2017. FtsH2-Dependent Proteolysis of EXECUTER1 Is Essential in Mediating Singlet Oxygen-Triggered Retrograde Signaling in Arabidopsis thaliana. Frontiers in plant science 8, 1145.

Dogra V, Li M, Singh S, Li M, Kim C. 2019. Oxidative post-translational modification of EXECUTER1 is required for singlet oxygen sensing in plastids. Nature Communications $\mathbf{1 0}$, 2834.

Dourmap C, Roque S, Morin A, Caubrière D, Kerdiles M, Béguin K, Perdoux R, Reynoud N, Bourdet L, Audebert P-A, Moullec JL, Couée I. 2020. Stress signalling dynamics of the mitochondrial electron transport chain and oxidative phosphorylation system in higher plants. Annals of Botany 125, 721-736.

\section{Dubiella U, Seybold H, Durian G, Komander E, Lassig R, Witte C-P, Schulze WX,} Romeis T. 2013. Calcium-dependent protein kinase/NADPH oxidase activation circuit is required for rapid defense signal propagation. Proceedings of the National Academy of Sciences 110, 8744-8749. 
Edwards EA, Rawsthorne S, Mullineaux PM. 1990. Subcellular distribution of multiple forms of glutathione reductase in leaves of pea (Pisum sativum L.). Planta 180, 278-284.

El-Esawi M, Arthaut L-D, Jourdan N, d'Harlingue A, Link J, Martino CF, Ahmad M. 2017. Blue-light induced biosynthesis of ROS contributes to the signaling mechanism of Arabidopsis cryptochrome. Scientific Reports 7, 13875.

Estavillo GM, Crisp PA, Pornsiriwong W, Wirtz M, Collinge D, Carrie C, Giraud E, Whelan J, David P, Javot H, Brearley C, Hell R, Marin E, Pogson BJ. 2011. Evidence for a SAL1-PAP Chloroplast Retrograde Pathway That Functions in Drought and High Light Signaling in \&lt;em\&gt;Arabidopsis\&lt;/em\&gt. The Plant Cell 23, 3992-4012.

Exposito-Rodriguez M, Laissue PP, Yvon-Durocher G, Smirnoff N, Mullineaux PM. 2017. Photosynthesis-dependent H2O2 transfer from chloroplasts to nuclei provides a highlight signalling mechanism. Nature Communications 8, 49.

Farmer EE, Mueller MJ. 2013. ROS-Mediated Lipid Peroxidation and RES-Activated Signaling. Annual Review of Plant Biology 64, 429-450.

Field LS, Furukawa Y, O'Halloran TV, Culotta VC. 2003. Factors controlling the uptake of yeast copper/zinc superoxide dismutase into mitochondria. Journal of Biological Chemistry 278, 28052-28059.

Fischer BB, Hideg É, Krieger-Liszkay A. 2013. Production, Detection, and Signaling of Singlet Oxygen in Photosynthetic Organisms. Antioxidants \& Redox Signaling 18, 2145 2162.

Fischer BB, Ledford HK, Wakao S, Huang SG, Casero D, Pellegrini M, Merchant SS, Koller A, Eggen RIL, Niyogi KK. 2012. SINGLET OXYGEN RESISTANT 1 links reactive electrophile signaling to singlet oxygen acclimation in Chlamydomonas reinhardtii. Proceedings of the National Academy of Sciences, 201116843.

Flügel F, Timm S, Arrivault S, Florian A, Stitt M, Fernie AR, Bauwe H. 2017. The Photorespiratory Metabolite 2-Phosphoglycolate Regulates Photosynthesis and Starch Accumulation in Arabidopsis. The Plant Cell 29, 2537-2551. 
Foyer CH, Halliwell B. 1976. The presence of glutathione and glutathione reductase in chloroplasts: A proposed role in ascorbic acid metabolism. Planta 133, 21-25.

Foyer CH, Karpinska B, Krupinska K. 2014. The functions of WHIRLY1 and REDOXRESPONSIVE TRANSCRIPTION FACTOR 1 in cross tolerance responses in plants: a hypothesis. Philosophical transactions of the Royal Society of London. Series B, Biological sciences 369, 20130226.

Foyer CH, Noctor G. 2003. Redox sensing and signalling associated with reactive oxygen in chloroplasts, peroxisomes and mitochondria. Physiologia Plantarum 119, 355-364.

Gaber A, Ogata T, Maruta T, Yoshimura K, Tamoi M, Shigeoka S. 2012. The Involvement of Arabidopsis Glutathione Peroxidase 8 in the Suppression of Oxidative Damage in the Nucleus and Cytosol. Plant and Cell Physiology 53, 1596-1606.

Gémes K, Kim YJ, Park KY, Moschou PN, Andronis E, Valassaki C, Roussis A, Roubelakis-Angelakis KA. 2016. An NADPH-Oxidase/Polyamine Oxidase Feedback Loop Controls Oxidative Burst Under Salinity. Plant physiology 172, 1418-1431.

Giacomelli L, Masi A, Ripoll DR, Lee MJ, van Wijk KJ. 2007. Arabidopsis thaliana deficient in two chloroplast ascorbate peroxidases shows accelerated light-induced necrosis when levels of cellular ascorbate are low. Plant Molecular Biology 65, 627-644.

Gigolashvili T, Geier M, Ashykhmina N, Frerigmann H, Wulfert S, Krueger S, Mugford SG, Kopriva S, Haferkamp I, Flügge U-I. 2012. The Arabidopsis Thylakoid ADP/ATP Carrier TAAC Has an Additional Role in Supplying Plastidic Phosphoadenosine 5'Phosphosulfate to the Cytosol. The Plant Cell 24, 4187-4204.

Giraud E, Ho LHM, Clifton R, Carroll A, Estavillo G, Tan Y-F, Howell KA, Ivanova A, Pogson BJ, Millar AH, Whelan J. 2008. The Absence of ALTERNATIVE OXIDASE1a in Arabidopsis Results in Acute Sensitivity to Combined Light and Drought Stress. Plant physiology 147, 595-610.

Girolomoni L, Cazzaniga S, Pinnola A, Perozeni F, Ballottari M, Bassi R. 2019. LHCSR3 is a nonphotochemical quencher of both photosystems in Chlamydomonas reinhardtii. Proceedings of the National Academy of Sciences 116, 4212-4217. 
Grondin A, Rodrigues O, Verdoucq L, Merlot S, Leonhardt N, Maurel C. 2015. Aquaporins Contribute to ABA-Triggered Stomatal Closure through OST1-Mediated Phosphorylation. The Plant Cell 27, 1945-1954.

Hagemann M, Weber APM, Eisenhut M. 2016. Photorespiration: origins and metabolic integration in interacting compartments. Journal of Experimental Botany 67, 2915-2918.

Halliwell B. 2006. Reactive Species and Antioxidants. Redox Biology Is a Fundamental Theme of Aerobic Life. Plant physiology 141, 312-322.

Halliwell B, Foyer CH. 1976. Ascorbic acid, metal ions and the superoxide radical. The Biochemical journal 155, 697-700.

Hänsch R, Lang C, Riebeseel E, Lindigkeit R, Gessler A, Rennenberg H, Mendel RR. 2006. Plant Sulfite Oxidase as Novel Producer of H2O2: COMBINATION OF ENZYME CATALYSIS WITH A SUBSEQUENT NON-ENZYMATIC REACTION STEP. Journal of Biological Chemistry 281, 6884-6888.

Hernandez-Marin E, Martínez A. 2012. Carbohydrates and Their Free Radical Scavenging Capability: A Theoretical Study. The Journal of Physical Chemistry B 116, 9668-9675.

Holland HD. 2006. The oxygenation of the atmosphere and oceans. Philosophical transactions of the Royal Society of London. Series B, Biological sciences 361, 903-915.

Huang C-H, Kuo W-Y, Weiss C, Jinn T-L. 2012. Copper Chaperone-Dependent and Independent Activation of Three Copper-Zinc Superoxide Dismutase Homologs Localized in Different Cellular Compartments in Arabidopsis. Plant physiology 158, 737-746.

Huang J, Willems P, Wei B, Tian C, Ferreira RB, Bodra N, Martínez Gache SA, Wahni K, Liu K, Vertommen D, Gevaert K, Carroll KS, Van Montagu M, Yang J, Van Breusegem F, Messens J. 2019. Mining for protein S-sulfenylation in Arabidopsis uncovers redox-sensitive sites. Proceedings of the National Academy of Sciences 116, 21256-21261.

\section{Iñarrea P, Moini H, Rettori D, Han D, Martínez J, García I, Fernández-Vizarra E,} Iturralde M, Cadenas E. 2005. Redox activation of mitochondrial intermembrane space $\mathrm{Cu}, \mathrm{Zn}$-superoxide dismutase. The Biochemical journal 387, 203-209. 
Iñiguez C, Capó-Bauçà S, Niinemets Ü, Stoll H, Aguiló-Nicolau P, Galmés J. 2020. Evolutionary trends in RuBisCO kinetics and their co-evolution with $\mathrm{CO} 2$ concentrating mechanisms. The Plant Journal 101, 897-918.

Jaipargas E-A, Mathur N, Bou Daher F, Wasteneys GO, Mathur J. 2016. High Light Intensity Leads to Increased Peroxule-Mitochondria Interactions in Plants. Frontiers in cell and developmental biology 4, 6-6.

Jiang J, Rodriguez-Furlan C, Wang J-Z, de Souza A, Ke H, Pasternak T, Lasok H, Ditengou FA, Palme K, Dehesh K. 2018. Interplay of the two ancient metabolites auxin and MEcPP regulates adaptive growth. Nature Communications 9, 2262.

Jiang J, Xiao Y, Chen H, Hu W, Zeng L, Ke H, Ditengou FA, Devisetty U, Palme K, Maloof J, Dehesh K. 2020. Retrograde Induction of phyB Orchestrates Ethylene-Auxin Hierarchy to Regulate Growth. Plant physiology 183, 1268-1280.

Jimenez A, Hernandez JA, Del Rio LA, Sevilla F. 1997. Evidence for the Presence of the Ascorbate-Glutathione Cycle in Mitochondria and Peroxisomes of Pea Leaves. Plant physiology 114, 275-284.

Jourdan N, Martino CF, El-Esawi M, Witczak J, Bouchet P-E, d'Harlingue A, Ahmad M. 2015. Blue-light dependent ROS formation by Arabidopsis cryptochrome-2 may contribute toward its signaling role. Plant signaling \& behavior 10, e1042647.

Kadota Y, Shirasu K, Zipfel C. 2015. Regulation of the NADPH Oxidase RBOHD During Plant Immunity. Plant and Cell Physiology 56, 1472-1480.

Kadota Y, Sklenar J, Derbyshire P, Stransfeld L, Asai S, Ntoukakis V, Jones Jonathan D, Shirasu K, Menke F, Jones A, Zipfel C. 2014. Direct Regulation of the NADPH Oxidase RBOHD by the PRR-Associated Kinase BIK1 during Plant Immunity. Molecular Cell 54, 43-55.

Kangasjärvi S, Lepistö A, Hännikäinen K, Piippo M, Luomala E-M, Aro E-M, Rintamäki E. 2008. Diverse roles for chloroplast stromal and thylakoid-bound ascorbate peroxidases in plant stress responses. Biochemical Journal 412, 275-285. 
Kärkönen A, Kuchitsu K. 2015. Reactive oxygen species in cell wall metabolism and development in plants. Phytochemistry 112, 22-32.

Kato Y, Sakamoto W. 2009. Protein Quality Control in Chloroplasts: A Current Model of D1 Protein Degradation in the Photosystem II Repair Cycle. The Journal of Biochemistry 146, 463-469.

Kaurilind E, Xu E, Brosché M. 2015. A genetic framework for H2O2 induced cell death in Arabidopsis thaliana. BMC Genomics 16, 837.

Kerchev P, Waszczak C, Lewandowska A, Willems P, Shapiguzov A, Li Z, Alseekh S, Mühlenbock P, Hoeberichts FA, Huang J, Van Der Kelen K, Kangasjärvi J, Fernie AR, De Smet R, Van de Peer Y, Messens J, Van Breusegem F. 2016. Lack of GLYCOLATE OXIDASE1, but Not GLYCOLATE OXIDASE2, Attenuates the Photorespiratory Phenotype of CATALASE2-Deficient Arabidopsis. Plant physiology 171, 1704-1719.

Kern R, Facchinelli F, Delwiche C, Weber APM, Bauwe H, Hagemann M. 2020. Evolution of Photorespiratory Glycolate Oxidase among Archaeplastida. Plants 9, 106.

Kim C, Meskauskiene R, Zhang S, Lee KP, Lakshmanan Ashok M, Blajecka K, Herrfurth C, Feussner I, Apel K. 2012. Chloroplasts of Arabidopsis Are the Source and a Primary Target of a Plant-Specific Programmed Cell Death Signaling Pathway. The Plant Cell 24, 3026-3039.

Kimura S, Hunter K, Vaahtera L, Tran HC, Citterico M, Vaattovaara A, Rokka A, Stolze SC, Harzen A, Meißner L, Wilkens MMT, Hamann T, Toyota M, Nakagami H, Wrzaczek M. 2020. CRK2 and C-terminal Phosphorylation of NADPH Oxidase RBOHD Regulate Reactive Oxygen Species Production in Arabidopsis. The Plant Cell 32, 1063-1080.

Krieger-Liszkay A, Trebst A. 2006. Tocopherol is the scavenger of singlet oxygen produced by the triplet states of chlorophyll in the PSII reaction centre. Journal of Experimental Botany 57, 1677-1684.

Krupinska K, Blanco NE, Oetke S, Zottini M. 2020. Genome communication in plants mediated by organelle-n-ucleus-located proteins. Philosophical Transactions of the Royal Society B: Biological Sciences 375, 20190397. 
Kumar A, Prasad A, Sedlářová M, Pospíšil P. 2019. Characterization of Protein Radicals in Arabidopsis. Frontiers in Physiology 10.

Laloi C, Havaux M. 2015. Key players of singlet oxygen-induced cell death in plants. Frontiers in plant science 6, 39.

Laloi C, Rayapuram N, Chartier Y, Grienenberger JM, Bonnard G, Meyer Y. 2001. Identification and characterization of a mitochondrial thioredoxin system in plants. Proceedings of the National Academy of Sciences of the United States of America 98, 1414414149.

Larosa V, Meneghesso A, La Rocca N, Steinbeck J, Hippler M, Szabò I, Morosinotto T. 2018. Mitochondria Affect Photosynthetic Electron Transport and Photosensitivity in a Green Alga. Plant physiology 176, 2305-2314.

Larosa V, Remacle C. 2018. Insights into the respiratory chain and oxidative stress. Bioscience Reports 38, BSR20171492.

Lecler R, Vigeolas H, Emonds-Alt B, Cardol P, Remacle C. 2012. Characterization of an internal type-II NADH dehydrogenase from Chlamydomonas reinhardtii mitochondria. Current Genetics 58, 205-216.

Lee KP, Kim C, Landgraf F, Apel K. 2007. EXECUTER1- and EXECUTER2-dependent transfer of stress-related signals from the plastid to the nucleus of Arabidopsis thaliana. Proceedings of the National Academy of Sciences 104, 10270-10275.

Leister D. 2017. Piecing the Puzzle Together: The Central Role of Reactive Oxygen Species and Redox Hubs in Chloroplast Retrograde Signaling. Antioxidants \& Redox Signaling 30, 1206-1219.

López-Huertas E, Corpas FJ, Sandalio LM, Del Río LA. 1999. Characterization of membrane polypeptides from pea leaf peroxisomes involved in superoxide radical generation. The Biochemical journal 337, 531-536.

Luo G, Ono S, Beukes NJ, Wang DT, Xie S, Summons RE. 2016. Rapid oxygenation of Earth's atmosphere 2.33 billion years ago. Science Advances 2, e1600134. 
Lv F, Zhou J, Zeng L, Xing D. 2015. $\beta$-cyclocitral upregulates salicylic acid signalling to enhance excess light acclimation in Arabidopsis. Journal of Experimental Botany 66, 47194732.

Mano Ji, Biswas MS, Sugimoto K. 2019. Reactive Carbonyl Species: A Missing Link in ROS Signaling. Plants (Basel, Switzerland) 8, 391.

Martins L, Trujillo-Hernandez JA, Reichheld J-P. 2018. Thiol Based Redox Signaling in Plant Nucleus. Frontiers in plant science 9, 705.

Maruta T, Sawa Y, Shigeoka S, Ishikawa T. 2016. Diversity and Evolution of Ascorbate Peroxidase Functions in Chloroplasts: More Than Just a Classical Antioxidant Enzyme? Plant and Cell Physiology 57, 1377-1386.

\section{Maruta T, Tanouchi A, Tamoi M, Yabuta Y, Yoshimura K, Ishikawa T, Shigeoka S.} 2010. Arabidopsis Chloroplastic Ascorbate Peroxidase Isoenzymes Play a Dual Role in Photoprotection and Gene Regulation under Photooxidative Stress. Plant and Cell Physiology 51, 190-200.

\section{Massoz S, Hanikenne M, Bailleul B, Coosemans N, Radoux M, Miranda-Astudillo H,} Cardol P, Larosa V, Remacle C. 2017. In vivo chlorophyll fluorescence screening allows the isolation of a Chlamydomonas mutant defective for NDUFAF3, an assembly factor involved in mitochondrial complex I assembly. The Plant Journal 92, 584-595.

Matros A, Peshev D, Peukert M, Mock H-P, Van den Ende W. 2015. Sugars as hydroxyl radical scavengers: proof-of-concept by studying the fate of sucralose in Arabidopsis. The Plant Journal 82, 822-839.

\section{Meng X, Li L, De Clercq I, Narsai R, Xu Y, Hartmann A, Claros DL, Custovic E,} Lewsey MG, Whelan J, Berkowitz O. 2019. ANAC017 Coordinates Organellar Functions and Stress Responses by Reprogramming Retrograde Signaling. Plant physiology 180, 634653.

Meyer Y, Belin C, Delorme-Hinoux V, Reichheld JP, Riondet C. 2012. Thioredoxin and glutaredoxin systems in plants: molecular mechanisms, crosstalks, and functional significance. Antioxidants \& Redox Signaling 17, 1124-1160. 
Mhamdi A, Queval G, Chaouch S, Vanderauwera S, Van Breusegem F, Noctor G. 2010. Catalase function in plants: a focus on Arabidopsis mutants as stress-mimic models. Journal of Experimental Botany 61, 4197-4220.

Mielecki J, Gawroński P, Karpiński S. 2020. Retrograde Signaling: Understanding the Communication between Organelles. International journal of molecular sciences 21, 6173.

Miller G, Schlauch K, Tam R, Cortes D, Torres MA, Shulaev V, Dangl JL, Mittler R. 2009. The Plant NADPH Oxidase RBOHD Mediates Rapid Systemic Signaling in Response to Diverse Stimuli. Science Signaling 2, ra45.

Mittler R. 2017. ROS Are Good. Trends in Plant Science 22, 11-19.

Mittler R, Vanderauwera S, Gollery M, Van Breusegem F. 2004. Reactive oxygen gene network of plants. Trends in Plant Science 9, 490-498.

Mittova V, Theodoulou FL, Kiddle G, Volokita M, Tal M, Foyer CH, Guy M. 2004. Comparison of mitochondrial ascorbate peroxidase in the cultivated tomato, Lycopersicon esculentum, and its wild, salt-tolerant relative, L. pennellii- a role for matrix isoforms in protection against oxidative damage. Plant, Cell \& Environment 27, 237-250.

Møller IM. 2001. PLANT MITOCHONDRIA AND OXIDATIVE STRESS: Electron Transport, NADPH Turnover, and Metabolism of Reactive Oxygen Species. Annu Rev Plant Physiol Plant Mol Biol 52, 561-591.

Møller IM, Rasmusson AG, Fredlund KM. 1993. NAD(P)H-ubiquinone oxidoreductases in plant mitochondria. Journal of Bioenergetics and Biomembranes 25, 377-384.

Monte I, Kneeshaw S, Franco-Zorrilla JM, Chini A, Zamarreño AM, García-Mina JM, Solano R. 2020. An Ancient COI1-Independent Function for Reactive Electrophilic Oxylipins in Thermotolerance. Current Biology 30, 962-971.e963.

Morales J, Kadota Y, Zipfel C, Molina A, Torres M-A. 2016. The Arabidopsis NADPH oxidases RbohD and RbohF display differential expression patterns and contributions during plant immunity. Journal of Experimental Botany 67, 1663-1676. 
Müller K, Linkies A, Vreeburg RAM, Fry SC, Krieger-Liszkay A, Leubner-Metzger G. 2009. In Vivo Cell Wall Loosening by Hydroxyl Radicals during Cress Seed Germination and Elongation Growth. Plant physiology 150, 1855-1865.

Müller P, Li X-P, Niyogi KK. 2001. Non-Photochemical Quenching. A Response to Excess Light Energy. Plant physiology 125, 1558-1566.

Mullineaux PM, Exposito-Rodriguez M, Laissue PP, Smirnoff N. 2018. ROS-dependent signalling pathways in plants and algae exposed to high light: Comparisons with other eukaryotes. Free Radic Biol Med.

Muñoz P, Munné-Bosch S. 2020. Oxylipins in plastidial retrograde signaling. Redox Biology 37, 101717.

Murchie EH, Ruban AV. 2020. Dynamic non-photochemical quenching in plants: from molecular mechanism to productivity. The Plant Journal 101, 885-896.

Narendra S, Venkataramani S, Shen G, Wang J, Pasapula V, Lin Y, Kornyeyev D, Holaday AS, Zhang H. 2006. The Arabidopsis ascorbate peroxidase 3 is a peroxisomal membrane-bound antioxidant enzyme and is dispensable for Arabidopsis growth and development. Journal of Experimental Botany 57, 3033-3042.

Navrot N, Collin V, Gualberto J, Gelhaye E, Hirasawa M, Rey P, Knaff DB, Issakidis E, Jacquot JP, Rouhier N. 2006. Plant glutathione peroxidases are functional peroxiredoxins distributed in several subcellular compartments and regulated during biotic and abiotic stresses. Plant physiology 142, 1364-1379.

Ng S, Ivanova A, Duncan O, Law SR, Van Aken O, De Clercq I, Wang Y, Carrie C, Xu L, Kmiec B, Walker H, Van Breusegem F, Whelan J, Giraud E. 2013. A MembraneBound NAC Transcription Factor, ANAC017, Mediates Mitochondrial Retrograde Signaling in Arabidopsis. The Plant Cell 25, 3450-3471.

Nietzel T, Elsässer M, Ruberti C, Steinbeck J, Ugalde JM, Fuchs P, Wagner S, Ostermann L, Moseler A, Lemke P, Fricker MD, Müller-Schüssele SJ, Moerschbacher BM, Costa A, Meyer AJ, Schwarzländer M. 2019. The fluorescent protein sensor roGFP2Orp1 monitors in vivo $\mathrm{H} 2 \mathrm{O} 2$ and thiol redox integration and elucidates intracellular $\mathrm{H} 2 \mathrm{O} 2$ 
dynamics during elicitor-induced oxidative burst in Arabidopsis. New Phytologist 221, 16491664.

Nikkanen L, Rintamäki E. 2019. Chloroplast thioredoxin systems dynamically regulate photosynthesis in plants. Biochemical Journal 476, 1159-1172.

Noctor G, Foyer CH. 2016. Intracellular Redox Compartmentation and ROS-Related Communication in Regulation and Signaling. Plant physiology 171, 1581-1592.

Noctor G, Veljovic-Jovanovic S, Driscoll S, Novitskaya L, Foyer CH. 2002. Drought and Oxidative Load in the Leaves of C3 Plants: a Predominant Role for Photorespiration? Annals of Botany 89, 841-850.

Norman EG, Colman B. 1991. Purification and Characterization of Phosphoglycolate Phosphatase from the Cyanobacterium Coccochloris peniocystis. Plant physiology 95, 693698.

Nyathi Y, Baker A. 2006. Plant peroxisomes as a source of signalling molecules. Biochimica et Biophysica Acta (BBA) - Molecular Cell Research 1763, 1478-1495.

Ort DR, Baker NR. 2002. A photoprotective role for $\mathrm{O} 2$ as an alternative electron sink in photosynthesis? Current Opinion in Plant Biology 5, 193-198.

Ostrovsky D, Diomina G, Lysak E, Matveeva E, Ogrel O, Trutko S. 1998. Effect of oxidative stress on the biosynthesis of 2-C-methyl-d-erythritol-2,4-cyclopyrophosphate and isoprenoids by several bacterial strains. Archives of Microbiology 171, 69-72.

Pan R, Liu J, Wang S, Hu J. 2020. Peroxisomes: versatile organelles with diverse roles in plants. New Phytologist 225, 1410-1427.

Passardi F, Cosio C, Penel C, Dunand C. 2005. Peroxidases have more functions than a Swiss army knife. Plant Cell Reports 24, 255-265.

Peers G, Truong TB, Ostendorf E, Busch A, Elrad D, Grossman AR, Hippler M, Niyogi KK. 2009. An ancient light-harvesting protein is critical for the regulation of algal photosynthesis. Nature 462, 518-521. 
Phua SY, Yan D, Chan KX, Estavillo GM, Nambara E, Pogson BJ. 2018. The Arabidopsis SAL1-PAP Pathway: A Case Study for Integrating Chloroplast Retrograde, Light and Hormonal Signaling in Modulating Plant Growth and Development? Frontiers in plant science 9, 1171.

Pilon M, Ravet K, Tapken W. 2011. The biogenesis and physiological function of chloroplast superoxide dismutases. Biochimica et Biophysica Acta (BBA) - Bioenergetics 1807, 989-998.

Podgórska A, Burian M, Szal B. 2017. Extra-Cellular But Extra-Ordinarily Important for Cells: Apoplastic Reactive Oxygen Species Metabolism. Frontiers in plant science 8, 1353.

\section{Podgórska A, Ostaszewska-Bugajska M, Borysiuk K, Tarnowska A, Jakubiak M,}

Burian M, Rasmusson AG, Szal B. 2018. Suppression of External NADPH DehydrogenaseNDB1 in Arabidopsis thaliana Confers Improved Tolerance to Ammonium Toxicity via Efficient Glutathione/Redox Metabolism. International journal of molecular sciences 19, 1412.

Pogson BJ, Woo NS, Förster B, Small ID. 2008. Plastid signalling to the nucleus and beyond. Trends in Plant Science 13, 602-609.

\section{Pornsiriwong W, Estavillo GM, Chan KX, Tee EE, Ganguly D, Crisp PA, Phua SY,} Zhao C, Qiu J, Park J, Yong MT, Nisar N, Yadav AK, Schwessinger B, Rathjen J, Cazzonelli CI, Wilson PB, Gilliham M, Chen Z-H, Pogson BJ. 2017. A chloroplast retrograde signal, 3'-phosphoadenosine 5'-phosphate, acts as a secondary messenger in abscisic acid signaling in stomatal closure and germination. eLife 6, e23361.

Pulido P, Cazalis R, Cejudo FJ. 2009. An antioxidant redox system in the nucleus of wheat seed cells suffering oxidative stress. The Plant Journal 57, 132-145.

Puntarulo S, Sánchez RA, Boveris A. 1988. Hydrogen Peroxide Metabolism in Soybean Embryonic Axes at the Onset of Germination. Plant physiology 86, 626-630.

Queval G, Issakidis-Bourguet E, Hoeberichts FA, Vandorpe M, Gakière B, Vanacker H, Miginiac-Maslow M, Van Breusegem F, Noctor G. 2007. Conditional oxidative stress responses in the Arabidopsis photorespiratory mutant cat 2 demonstrate that redox state is a 
key modulator of daylength-dependent gene expression, and define photoperiod as a crucial factor in the regulation of $\mathrm{H} 2 \mathrm{O} 2$-induced cell death. The Plant Journal 52, 640-657.

Ramel F, Birtic S, Ginies C, Soubigou-Taconnat L, Triantaphylidès C, Havaux M. 2012. Carotenoid oxidation products are stress signals that mediate gene responses to singlet oxygen in plants. Proceedings of the National Academy of Sciences 109, 5535-5540.

Rasmusson AG, Geisler DA, Møller IM. 2008. The multiplicity of dehydrogenases in the electron transport chain of plant mitochondria. Mitochondrion 8, 47-60.

Rea G, Antonacci A, Lambreva MD, Mattoo AK. 2018. Features of cues and processes during chloroplast-mediated retrograde signaling in the alga Chlamydomonas. Plant Science 272, 193-206.

\section{Rivasseau C, Seemann M, Boisson A-M, Streb P, Gout E, Douce R, Rohmer M, Bligny} R. 2009. Accumulation of 2-C-methyl-d-erythritol 2,4-cyclodiphosphate in illuminated plant leaves at supraoptimal temperatures reveals a bottleneck of the prokaryotic methylerythritol 4phosphate pathway of isoprenoid biosynthesis. Plant, Cell \& Environment 32, 82-92.

Roach T, Krieger-Liszkay A. 2014. Regulation of photosynthetic electron transport and photoinhibition. Current protein \& peptide science 15, 351-362.

Roach T, Stöggl W, Baur T, Kranner I. 2018. Distress and eustress of reactive electrophiles and relevance to light stress acclimation via stimulation of thiol/disulphide-based redox defences. Free Radical Biology and Medicine 122, 65-73.

Rochaix J-D. 2007. Role of thylakoid protein kinases in photosynthetic acclimation. FEBS Letters 581, 2768-2775.

Rodrigues O, Reshetnyak G, Grondin A, Saijo Y, Leonhardt N, Maurel C, Verdoucq L. 2017. Aquaporins facilitate hydrogen peroxide entry into guard cells to mediate ABA- and pathogen-triggered stomatal closure. Proceedings of the National Academy of Sciences 114, 9200-9205.

Rodríguez-Serrano M, Romero-Puertas MC, Pastori GM, Corpas FJ, Sandalio LM, del Río LA, Palma JM. 2007. Peroxisomal membrane manganese superoxide dismutase: 
characterization of the isozyme from watermelon (Citrullus lanatus Schrad.) cotyledons. Journal of Experimental Botany 58, 2417-2427.

Rodríguez-Serrano M, Romero-Puertas MC, Sanz-Fernández M, Hu J, Sandalio LM. 2016. Peroxisomes Extend Peroxules in a Fast Response to Stress via a Reactive Oxygen Species-Mediated Induction of the Peroxin PEX11a. Plant physiology 171, 1665-1674.

\section{Rouhier N, Villarejo A, Srivastava M, Gelhaye E, Keech O, Droux M, Finkemeier I,} Samuelsson G, Dietz KJ, Jacquot JP, Wingsle G. 2005. Identification of plant glutaredoxin targets. Antioxidants \& Redox Signaling 7, 919-929.

Ruban AV, Johnson MP. 2009. Dynamics of higher plant photosystem cross-section associated with state transitions. Photosynthesis Research 99, 173-183.

Salinas T, Larosa V, Cardol P, Maréchal-Drouard L, Remacle C. 2014. Respiratorydeficient mutants of the unicellular green alga Chlamydomonas: A review. Biochimie 100, 207-218.

Sandalio LM, Fernández VM, Rupérez FL, Del Río LA. 1988. Superoxide free radicals are produced in glyoxysomes. Plant physiology 87, 1-4.

Sandalio LM, Peláez-Vico MA, Molina-Moya E, Romero-Puertas MC. 2021.

Peroxisomes as Redox-Signaling Nodes in Intracellular Communication and Stress Responses. Plant physiology kiab060.

Schertl P, Braun H-P. 2014. Respiratory electron transfer pathways in plant mitochondria. Frontiers in plant science 5, 163.

Schimmeyer J, Bock R, Meyer EH. 2016. L-Galactono-1,4-lactone dehydrogenase is an assembly factor of the membrane arm of mitochondrial complex I in Arabidopsis. Plant Molecular Biology 90, 117-126.

Schnaubelt D, Queval G, Dong Y, Diaz-Vivancos P, Makgopa ME, Howell G, De Simone A, Bai J, Hannah MA, Foyer CH. 2015. Low glutathione regulates gene expression and the redox potentials of the nucleus and cytosol in Arabidopsis thaliana. Plant, Cell \& Environment 38, 266-279. 
Scuffi D, Nietzel T, Di Fino LM, Meyer AJ, Lamattina L, Schwarzländer M, Laxalt AM, García-Mata C. 2018. Hydrogen Sulfide Increases Production of NADPH OxidaseDependent Hydrogen Peroxide and Phospholipase D-Derived Phosphatidic Acid in Guard Cell Signaling. Plant physiology 176, 2532-2542.

Seemann M, Wegner P, Schünemann V, Bui BTS, Wolff M, Marquet A, Trautwein AX, Rohmer M. 2005. Isoprenoid biosynthesis in chloroplasts via the methylerythritol phosphate pathway: the (E)-4-hydroxy-3-methylbut-2-enyl diphosphate synthase (GcpE) from Arabidopsis thaliana is a $[4 \mathrm{Fe}-4 \mathrm{~S}]$ protein. JBIC Journal of Biological Inorganic Chemistry 10, 131-137.

Sewelam N, Jaspert N, Van Der Kelen K, Tognetti VB, Schmitz J, Frerigmann H, Stahl E, Zeier J, Van Breusegem F, Maurino VG. 2014. Spatial H2O2 Signaling Specificity: $\mathrm{H} 2 \mathrm{O} 2$ from Chloroplasts and Peroxisomes Modulates the Plant Transcriptome Differentially. Molecular Plant 7, 1191-1210.

Shao N, Duan GY, Bock R. 2013. A Mediator of Singlet Oxygen Responses in Chlamydomonas reinhardtii and Arabidopsis Identified by a Luciferase-Based Genetic Screen in Algal Cells. The Plant Cell 25, 4209-4226.

Shapiguzov A, Vainonen JP, Hunter K, Tossavainen H, Tiwari A, Järvi S, Hellman M, Aarabi F, Alseekh S, Wybouw B, Van Der Kelen K, Nikkanen L, Krasensky-Wrzaczek J, Sipari N, Keinänen M, Tyystjärvi E, Rintamäki E, De Rybel B, Salojärvi J, Van Breusegem F, Fernie AR, Brosché M, Permi P, Aro E-M, Wrzaczek M, Kangasjärvi J. 2019. Arabidopsis RCD1 coordinates chloroplast and mitochondrial functions through interaction with ANAC transcription factors. eLife 8, e43284.

Shirao M, Kuroki S, Kaneko K, Kinjo Y, Tsuyama M, Forster B, Takahashi S, Badger MR. 2013. Gymnosperms have increased capacity for electron leakage to oxygen (Mehler and PTOX reactions) in photosynthesis compared with angiosperms. Plant Cell Physiol 54, 1152-1163.

Shumbe L, D'Alessandro S, Shao N, Chevalier A, Ksas B, Bock R, Havaux M. 2017. METHYLENE BLUE SENSITIVITY 1 (MBS1) is required for acclimation of Arabidopsis to singlet oxygen and acts downstream of $\beta$-cyclocitral. Plant, Cell \& Environment 40, 216-226. 
Sierla M, Waszczak C, Vahisalu T, Kangasjärvi J. 2016. Reactive Oxygen Species in the Regulation of Stomatal Movements. Plant physiology 171, 1569-1580.

Smirnoff N. 2018. Ascorbic acid metabolism and functions: A comparison of plants and mammals. Free radical biology \& medicine 122, 116-129.

Solymosi K, Schoefs B. 2010. Etioplast and etio-chloroplast formation under natural conditions: the dark side of chlorophyll biosynthesis in angiosperms. Photosynthesis Research 105, 143-166.

Soufari H, Parrot C, Kuhn L, Waltz F, Hashem Y. 2020. Specific features and assembly of the plant mitochondrial complex I revealed by cryo-EM. Nature Communications 11, 5195.

Stirbet A, Lazár D, Guo Y, Govindjee G. 2020. Photosynthesis: basics, history and modelling. Annals of Botany 126, 511-537.

Su T, Li W, Wang P, Ma C. 2019. Dynamics of Peroxisome Homeostasis and Its Role in Stress Response and Signaling in Plants. Frontiers in plant science 10, 705.

Sun H, Yang Y-J, Huang W. 2020. The water-water cycle is more effective in regulating redox state of photosystem I under fluctuating light than cyclic electron transport. Biochimica et Biophysica Acta (BBA) - Bioenergetics 1861, 148235.

Takahashi S, Badger MR. 2011. Photoprotection in plants: a new light on photosystem II damage. Trends in Plant Science 16, 53-60.

Torres MA, Dangl JL, Jones JDG. 2002. Arabidopsis gp91phox homologues AtrbohD and AtrbohF are required for accumulation of reactive oxygen intermediates in the plant defense response. Proceedings of the National Academy of Sciences 99, 517-522.

Tripathy BC, Oelmüller R. 2012. Reactive oxygen species generation and signaling in plants. Plant Signaling and Behaviour 7, 1621-1633.

Umbach AL, Fiorani F, Siedow JN. 2005. Characterization of transformed Arabidopsis with altered alternative oxidase levels and analysis of effects on reactive oxygen species in tissue. Plant physiology 139, 1806-1820. 
Van Aken O, Pogson BJ. 2017. Convergence of mitochondrial and chloroplastic ANAC017/PAP-dependent retrograde signalling pathways and suppression of programmed cell death. Cell Death \& Differentiation 24, 955-960.

Van Breusegem F, Dat JF. 2006. Reactive Oxygen Species in Plant Cell Death. Plant physiology 141, 384-390.

Van Leene J, Stals H, Eeckhout D, Persiau G, Van De Slijke E, Van Isterdael G, De Clercq A, Bonnet E, Laukens K, Remmerie N, Henderickx K, De Vijlder T, Abdelkrim A, Pharazyn A, Van Onckelen H, Inzé D, Witters E, De Jaeger G. 2007. A Tandem Affinity Purification-based Technology Platform to Study the Cell Cycle Interactome in Arabidopsis thaliana. Molecular \& Cellular Proteomics 6, 1226-1238.

Vishwakarma A, Tetali SD, Selinski J, Scheibe R, Padmasree K. 2015. Importance of the alternative oxidase (AOX) pathway in regulating cellular redox and ROS homeostasis to optimize photosynthesis during restriction of the cytochrome oxidase pathway in Arabidopsis thaliana. Annals of Botany 116, 555-569.

Wakao S, Chin BL, Ledford HK, Dent RM, Casero D, Pellegrini M, Merchant SS, Niyogi KK. 2014. Phosphoprotein SAK1 is a regulator of acclimation to singlet oxygen in Chlamydomonas reinhardtii. eLife 3, e02286.

Wang J-Z, Li B, Xiao Y, Ni Y, Ke H, Yang P, de Souza A, Bjornson M, He X, Shen Z, Balcke GU, Briggs SP, Tissier A, Kliebenstein DJ, Dehesh K. 2017. Initiation of ER Body Formation and Indole Glucosinolate Metabolism by the Plastidial Retrograde Signaling Metabolite, MEcPP. Molecular Plant 10, 1400-1416.

Wang J, Rajakulendran N, Amirsadeghi S, Vanlerberghe GC. 2011. Impact of mitochondrial alternative oxidase expression on the response of Nicotiana tabacum to cold temperature. Physiologia Plantarum 142, 339-351.

Wang L, Kim C, Xu X, Piskurewicz U, Dogra V, Singh S, Mahler H, Apel K. 2016. Singlet oxygen- and EXECUTER1-mediated signaling is initiated in grana margins and depends on the protease FtsH2. Proceedings of the National Academy of Sciences 113, E3792-E3800. 
Wang L, Leister D, Guan L, Zheng Y, Schneider K, Lehmann M, Apel K, Kleine T. 2020a. The Arabidopsis SAFEGUARD1 suppresses singlet oxygen-induced stress responses by protecting grana margins. Proceedings of the National Academy of Sciences 117, 69186927.

Wang Q, Lin C. 2020. Mechanisms of Cryptochrome-Mediated Photoresponses in Plants. Annual Review of Plant Biology 71, 103-129.

Wang W, Paschalidis K, Feng J-C, Song J, Liu J-H. 2019. Polyamine Catabolism in Plants: A Universal Process With Diverse Functions. Frontiers in plant science 10, 561.

Wang X, Li S, Liu Y, Ma C. 2015. Redox regulated peroxisome homeostasis. Redox Biology 4, 104-108.

Wang Y, Selinski J, Mao C, Zhu Y, Berkowitz O, Whelan J. 2020b. Linking mitochondrial and chloroplast retrograde signalling in plants. Philosophical Transactions of the Royal Society B: Biological Sciences 375, 20190410.

Waszczak C, Carmody M, Kangasjärvi J. 2018. Reactive Oxygen Species in Plant Signaling. Annual Review of Plant Biology 69, 209-236.

Waszczak C, Kerchev PI, Mühlenbock P, Hoeberichts FA, Van Der Kelen K, Mhamdi A, Willems P, Denecker J, Kumpf RP, Noctor G, Messens J, Van Breusegem F. 2016. SHORT-ROOT Deficiency Alleviates the Cell Death Phenotype of the Arabidopsis catalase2 Mutant under Photorespiration-Promoting Conditions. The Plant Cell 28, 1844-1859.

Wei B, Willems P, Huang J, Tian C, Yang J, Messens J, Van Breusegem F. 2020. Identification of Sulfenylated Cysteines in Arabidopsis thaliana Proteins Using a DisulfideLinked Peptide Reporter. Frontiers in plant science 11, 777.

Wendrich JR, Yang B, Vandamme N, Verstaen K, Smet W, Van de Velde C, Minne M, Wybouw B, Mor E, Arents HE, Nolf J, Van Duyse J, Van Isterdael G, Maere S, Saeys Y, De Rybel B. 2020. Vascular transcription factors guide plant epidermal responses to limiting phosphate conditions. Science 370, eaay4970. 


\section{Willems P, Mhamdi A, Stael S, Storme V, Kerchev P, Noctor G, Gevaert K, Van} Breusegem F. 2016. The ROS Wheel: Refining ROS Transcriptional Footprints. Plant physiology 171, 1720-1733.

Winger AM, Millar AH, Day DA. 2005. Sensitivity of plant mitochondrial terminal oxidases to the lipid peroxidation product 4-hydroxy-2-nonenal (HNE). The Biochemical journal 387, 865-870.

Winger AM, Taylor NL, Heazlewood JL, Day DA, Millar AH. 2007. The Cytotoxic Lipid Peroxidation Product 4-Hydroxy-2-nonenal Covalently Modifies a Selective Range of Proteins Linked to Respiratory Function in Plant Mitochondria. Journal of Biological Chemistry 282, 37436-37447.

Wingler A, Lea PJ, Quick WP, Leegood RC. 2000. Photorespiration: metabolic pathways and their role in stress protection. Philosophical Transactions of the Royal Society of London. Series B: Biological Sciences 355, 1517-1529.

Wollman F-A. 2001. State transitions reveal the dynamics and flexibility of the photosynthetic apparatus. The EMBO Journal 20, 3623-3630.

Wu Q, Lin J, Liu JZ, Wang X, Lim W, Oh M, Park J, Rajashekar CB, Whitham SA, Cheng NH, Hirschi KD, Park S. 2012. Ectopic expression of Arabidopsis glutaredoxin AtGRXS17 enhances thermotolerance in tomato. Plant Biotechnol J 10, 945-955.

Xiao Y, Savchenko T, Baidoo Edward EK, Chehab Wassim E, Hayden Daniel M, Tolstikov V, Corwin Jason A, Kliebenstein Daniel J, Keasling Jay D, Dehesh K. 2012. Retrograde Signaling by the Plastidial Metabolite MEcPP Regulates Expression of Nuclear Stress-Response Genes. Cell 149, 1525-1535.

Yabuta Y, Motoki T, Yoshimura K, Takeda T, Ishikawa T, Shigeoka S. 2002. Thylakoid membrane-bound ascorbate peroxidase is a limiting factor of antioxidative systems under photo-oxidative stress. The Plant Journal 32, 915-925.

Yoshida K, Watanabe CK, Hachiya T, Tholen D, Shibata M, Terashima I, Noguchi KO. 2011. Distinct responses of the mitochondrial respiratory chain to long- and short-term highlight environments in Arabidopsis thaliana. Plant, Cell \& Environment 34, 618-628. 
Zandalinas SI, Fichman Y, Mittler R. 2020. Vascular Bundles Mediate Systemic Reactive Oxygen Signaling during Light Stress. The Plant Cell 32, 3425-3435.

Zarepour M, Kaspari K, Stagge S, Rethmeier R, Mendel RR, Bittner F. 2010. Xanthine dehydrogenase AtXDH1 from Arabidopsis thaliana is a potent producer of superoxide anions via its NADH oxidase activity. Plant Molecular Biology 72, 301-310.

Zhang Z-S, Liu M-J, Scheibe R, Selinski J, Zhang L-T, Yang C, Meng X-L, Gao H-Y. 2017. Contribution of the Alternative Respiratory Pathway to PSII Photoprotection in C3 and C4 Plants. Molecular Plant 10, 131-142. 


\section{Figure Legends}

Fig. 1. Summary of the major ROS-producing and-quenching pathways in plant cells. In chloroplasts, the photosynthetic electron transport chain can produce reactive oxygen species (ROS) at both Photosystem II (PSII) and Photosystem I (PSI). At PSII, excited chlorophyll molecules transfer energy to triplet oxygen to produce singlet oxygen $\left({ }^{1} \mathrm{O}_{2}\right)$, which can be quenched by multiple pigment molecules. ${ }^{1} \mathrm{O}_{2}$ can also be produced when the photosensitizing biosynthetic intermediates of chlorophyll are exposed to light. At PSI, electron leakage to $\mathrm{O}_{2}$ results in superoxide $\left(\mathrm{O}_{2}{ }^{-}\right)$formation, which is converted to hydrogen peroxide $\left(\mathrm{H}_{2} \mathrm{O}_{2}\right)$ either via the action of SODs or by spontaneous dismutation. $\mathrm{H}_{2} \mathrm{O}_{2}$ can attack the iron (Fe) co-factor of SODs to form hydroxyl radicals $\left(\mathrm{OH}^{-}\right)$- also known as Fenton reaction. The incorporation of $\mathrm{O}_{2}$ rather than $\mathrm{CO}_{2}$ by Rubisco in chloroplasts leads to induction of the photorespiratory pathway; glycolate from chloroplasts is exported into peroxisomes where its conversion into glyoxylate is a major source of $\mathrm{H}_{2} \mathrm{O}_{2}$ in this compartment. Other enzymatic processes, such as sulfite and fatty acid oxidation, as well as polyamine degradation, also contribute to peroxisomal $\mathrm{H}_{2} \mathrm{O}_{2}$ production, Polyamine degradation by polyamine oxidases (PAO) also produces $\mathrm{H}_{2} \mathrm{O}_{2}$ in the cytosol. In mitochondria, Complexes I and III of the mitochondrial electron transport chain (mETC) both produce $\mathrm{O}_{2}{ }^{--}$which is then converted to $\mathrm{H}_{2} \mathrm{O}_{2}$. The apoplast is another major source of ROS; here the respiratory burst oxidase homologs $(\mathrm{RBOH})$ proteins catalyse $\mathrm{O}_{2}{ }^{--}$production. Similar to the other compartments, SODs are thought to be responsible for conversion of $\mathrm{O}_{2}{ }^{--}$to $\mathrm{H}_{2} \mathrm{O}_{2}$ in the apoplast, with PAO and peroxiredoxins (PRX) also contributing to apoplastic $\mathrm{H}_{2} \mathrm{O}_{2}$ production. Cryptochromes (CRY) have been implicated in ROS production in the nucleus, although the exact type of ROS being produced is unclear. $\mathrm{H}_{2} \mathrm{O}_{2}$ movement between subcellular compartments can be facilitated by aquaporins (AQP). The detoxification of $\mathrm{H}_{2} \mathrm{O}_{2}$ to water is achieved via similar mechanisms in the different subcellular compartments, with ascorbate peroxidase (APX), glutathione peroxidase (GPX), and/or PRX being the main enzymes involved. GPX and PRX utilise redox-sensitive cysteines in their active site to convert $\mathrm{H}_{2} \mathrm{O}_{2}$ to water; the oxidized cysteines are regenerated by thioredoxins and glutaredoxins which are themselves regenerated by other reductases using reducing power from PSI. In the peroxisomes, catalase (CAT) is an additional, and indeed the dominant, $\mathrm{H}_{2} \mathrm{O}_{2}$-detoxification enzyme. In the mitochondria, multiple alternative oxidoreductases, such as Alternative Oxidase 1a (AOX1a) also contribute to decreasing $\mathrm{O}_{2}{ }^{--}$and $\mathrm{H}_{2} \mathrm{O}_{2}$ production by removing excess electrons from the mETC. All black curved arrows denote electron transfer, straight black arrows indicate enzymatic 
reactions, grey arrows show movement, blue arrows indicate ROS detoxification steps and dashed lines denote putative events with components/players yet to be experimentally demonstrated. Other abbreviations: acyl-CoA oxidases (ACX), ferredoxin (Fd), glycolate oxidase (GOX), intermembrane space (IMS) stromal ascorbate peroxidase (sAPX), sulfite oxidase (SO), thylakoidal ascorbate peroxidase (tAPX), ubiquinone/ubiquinol (Q), 3phosphoglycerate (3-PGA), 2-phosphoglycolate (2-PG). Organelles are not drawn to scale.

Fig. 2. ROS-induced organelle-to-nucleus retrograde signalling pathways. In the chloroplast, both Photosystem II (PSII) and PSI-induced ROS are capable of activating different chloroplast-to-nucleus retrograde signals. Singlet oxygen $\left({ }^{1} \mathrm{O}_{2}\right)$ production at the grana margins leads to oxidation of the Executer 1 (Ex1) protein, which is then cleaved by the thylakoidal FtSH2 protease. An unknown Ex1 peptide fragment then initiates signalling to the nucleus to activate expression of a subset of Singlet Oxygen Responsive Genes (SORGs I) associated with regulation of cell death. Conversely, ${ }^{1} \mathrm{O}_{2}$ production by the PSII reaction center at the grana core is sensed via oxidative cleavage of $\beta$-carotene to produce $\beta$-cyclocitral $(\beta-\mathrm{CC})$ which is a volatile retrograde signal. $\beta$-CC can be rapidly converted to $\beta$-cyclocitric acid ( $\beta$-CCA). Both $\beta$-CC and $\beta$-CCA regulate the expression of a second subset of SORGs (SORGs II), which is distinct to those regulated by EX1. The regulation of SORGs II by $\beta$-CC is dependent on the cytosolic protein Methylene Blue Sensitive 1 (MBS1), whereas $\beta$-CCA functions independently of MBS1. $\beta$-CC also activates the expression of genes involved in xenobiotic detoxification responses. ROS produced from PSI are thought to decrease the activities of 4-hydroxy-3-methylbut-2-enyl diphosphate synthase (HDS) and SAL1 via redox regulation, thereby enabling accumulation of their respective substrates 2-C-methyl-Derythritol-2,4-cyclodiphosphate (MEcPP) and 3'-phosphoadenosine 5'-phosphate (PAP). Both of these metabolites function as retrograde signals which target a broad class of genes independent of ${ }^{1} \mathrm{O}_{2}$ but otherwise responsive to oxidative stress in chloroplasts termed Plastid Redox Associated Nuclear Genes (PRANGs). MEcPP -mediated signalling proceeds in the nucleus at least in part via the CAMTA transcription factor, but the mechanisms for intracellular transport and nuclear perception of MEcPP are still unknown. PAP transport between the chloroplast and the cytosol is mediated by PAPS/PAP transporter 1 (PAPST1) and PAPST2 transporters. In the nucleus, PAP binds to exoribonuclease enzymes (XRNs), which alters RNA Polymerase II (Pol II) activity thereby enabling up-regulation of a large number of PRANGs. Direct transfer of $\mathrm{H}_{2} \mathrm{O}_{2}$ from chloroplasts to the nucleus has been observed and is proposed to be a signalling mechanism, but nuclear receptors for $\mathrm{H}_{2} \mathrm{O}_{2}$ are 
currently unknown. ROS overproduction in mitochondria leads to activation of an unknown protease which releases the ANAC017 / ANAC013 transcription factors from their ER tethering. The truncated ANAC017 / ANAC013 proteins translocate to the nucleus, where they activate expression of Mitochondrial Dysfunction Stimulon (MDS) genes including Alternative Oxidase 1a (AOX1a). This mitochondrial signalling pathway is normally suppressed in the nucleus by RCD1, but activated during mitochondrial stress due to redoxmediated inactivation of RCD1 (possibly by nuclear $\mathrm{H}_{2} \mathrm{O}_{2}$ ). Another proposed regulator for this mitochondrial pathway is PAP, although the mechanism is still unclear. Mitochondria also contain PAP and SAL1, but it is not clear if mitochondrial SAL1 is similarly redoxregulated to enable PAP to function as a mitochondrial retrograde signal. Peroxisomes are sources of various potential signalling molecules, but their connection to peroxisomal ROS and hypothetical retrograde signalling from peroxisomes is still not clear. Red arrows/lines denote ROS-induced signalling events, blue arrow indicates ROS detoxification step, dashed lines denote putative events with components/players yet to be experimentally demonstrated, red fonts denote ROS-sensors, yellow boxes highlight signalling molecules. Other abbreviations: adenosine monophosphate (AMP), adenosine diphosphate (ADP), adenosine triphosphate (ATP), 4-hydroxyl-3-methyl-butenyl 1-diphosphate (HMBPP), 3'phosphoadenosine 5'-phosphosulfate (PAPS), reactive nitrogen species (RNS). Organelles are not drawn to scale. 


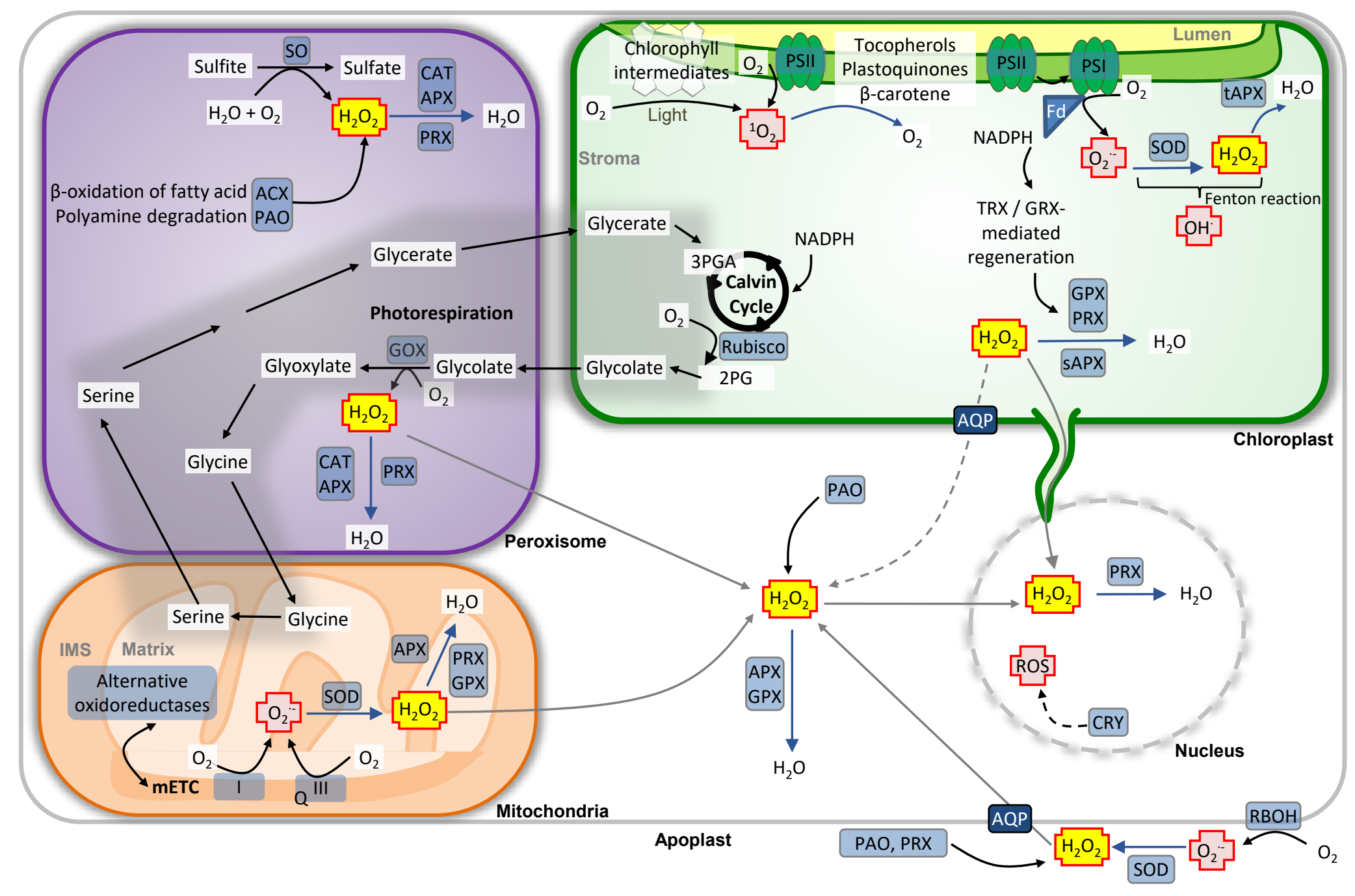


Fig. 1. Summary of the major ROS-producing and -quenching pathways in plant cells. In chloroplasts, the photosynthetic electron transport chain (ETC) can produce reactive oxygen species (ROS) at both photosystem II (PSII) and photosystem I (PSI). At PSII, excited chlorophyll molecules transfer energy to triplet oxygen to produce singlet oxygen $\left({ }^{1} \mathrm{O}_{2}\right)$, which can be quenched by multiple pigment molecules. ${ }^{1} \mathrm{O}_{2}$ can also be produced when the photosensitizing biosynthetic intermediates of chlorophyll are exposed to light. At PSI, electron leakage to $\mathrm{O}_{2}$ results in superoxide $\left(\mathrm{O}_{2} \cdot\right)$ formation, which is converted to hydrogen peroxide $\left(\mathrm{H}_{2} \mathrm{O}_{2}\right)$ either via the action of superoxide dismutases (SODs) or by spontaneous dismutation. $\mathrm{H}_{2} \mathrm{O}_{2}$ can attack the iron (Fe) cofactor of SODs to form hydroxyl radicals $\left(\mathrm{OH}^{-}\right)$- also known as Fenton reaction. The incorporation of $\mathrm{O}_{2}$ rather than $\mathrm{CO}_{2}$ by Rubisco in chloroplasts induces the photorespiratory pathway; glycolate from chloroplasts is exported into peroxisomes, where it is converted into glyoxylate and so is a major source of $\mathrm{H}_{2} \mathrm{O}_{2}$ in this compartment. Other enzymatic processes, such as sulfite and fatty acid oxidation, as well as polyamine degradation, also contribute to peroxisomal $\mathrm{H}_{2} \mathrm{O}_{2}$ production, Polyamine degradation by polyamine oxidases (PAOs) also produces $\mathrm{H}_{2} \mathrm{O}_{2}$ in the cytosol. In mitochondria, complexes I and III of the mitochondrial $(\mathrm{m})$ ETC both produce $\mathrm{O}_{2}{ }^{--}$that is then converted to $\mathrm{H}_{2} \mathrm{O}_{2}$. The apoplast is another major source of ROS; here the respiratory burst oxidase homolog $(\mathrm{RBOH})$ proteins catalyze $\mathrm{O}_{2}$ - production. Similarly to the other compartments, SODs are thought to be responsible for the conversion of $\mathrm{O}_{2}-\mathrm{H}_{2}$ to $\mathrm{H}_{2}$ in the apoplast, with PAOs and peroxiredoxins (PRXs) also generating apoplastic $\mathrm{H}_{2} \mathrm{O}_{2}$. Cryptochromes (CRY) have been implicated in ROS production in the nucleus, although the exact ROS type is unclear. $\mathrm{H}_{2} \mathrm{O}_{2}$ movement between subcellular compartments can be facilitated by aquaporins (AQPs). $\mathrm{H}_{2} \mathrm{O}_{2}$ is detoxified to water via similar mechanisms in the different subcellular compartments, with ascorbate peroxidase (APX), glutathione peroxidase (GPX), and/or PRX as the main enzymes involved. GPX and PRX utilize redox-sensitive cysteines in their active site to convert $\mathrm{H}_{2} \mathrm{O}_{2}$ to water; the oxidized cysteines are regenerated by thioredoxins and glutaredoxins, which are themselves regenerated by other reductases by means of the PSI reducing power. In the peroxisomes, catalase (CAT) is an additional, and indeed the dominant, $\mathrm{H}_{2} \mathrm{O}_{2}$ detoxification enzyme. In the mitochondria, multiple alternative oxidoreductases, such as Alternative Oxidase $1 a(A O X 1 a)$, also decrease $\mathrm{O}_{2}$-and $\mathrm{H}_{2} \mathrm{O}_{2}$ production by removing excess electrons from the $\mathrm{mETC}$. All black curved arrows denote electron transfer, straight black arrows indicate enzymatic reactions, grey arrows show movement, blue arrows indicate ROS detoxification steps and dashed lines denote putative events with components/players yet to be experimentally demonstrated. Abbreviations: ACX, acyl-CoA oxidases; Fd, ferredoxin, GOX, glycolate oxidase; IMS, intermembrane space; sAPX, stromal ascorbate peroxidase; SO, sulfite oxidase; tAPX, thylakoidal ascorbate peroxidase; Q, ubiquinone/ubiquinol; 3PGA, 3-phosphoglycerate; 2PG, 2-phosphoglycolate. Organelles are not drawn to scale. 
Grana margin

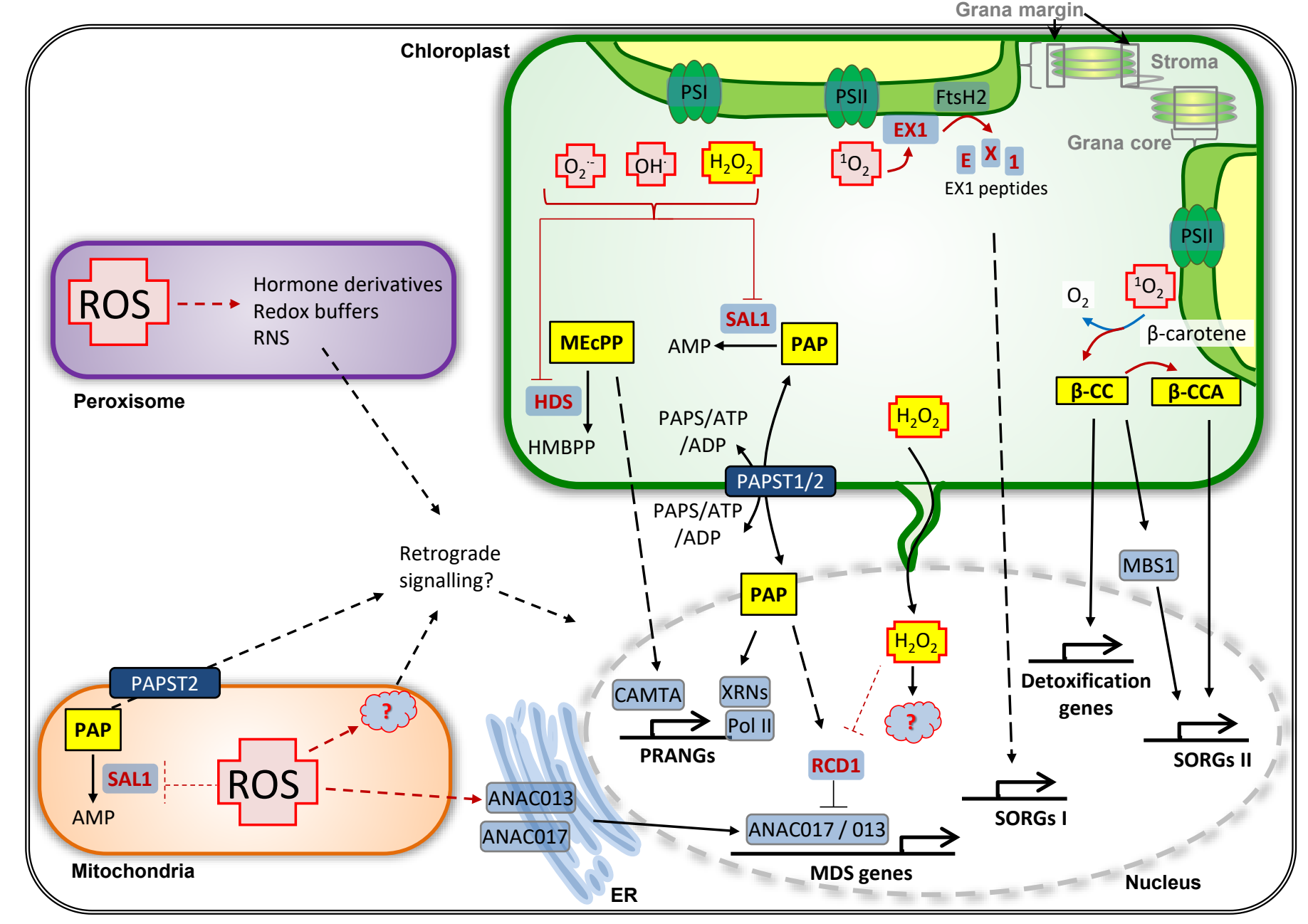


Fig. 2. ROS-induced organelle-to-nucleus retrograde signaling pathways. In the chloroplast, both photosystem II (PSII) and PSI-induced ROS can activate different chloroplast-to-nucleus retrograde signals. Singlet oxygen $\left({ }^{1} \mathrm{O}_{2}\right)$ production at the grana margins leads to oxidation of the Executer 1 (EX1) protein, which is cleaved by the thylakoidal FtSH2 protease. An unknown Ex1 peptide fragment initiates signaling to the nucleus to activate expression of a subset of Singlet Oxygen Responsive Genes (SORGs I) associated with the regulation of cell death. Conversely, ${ }^{1} \mathrm{O}_{2}$ production by the PSII reaction center at the grana core is sensed via oxidative cleavage of $\beta$-carotene to produce $\beta$-cyclocitral ( $\beta$ $\mathrm{CC}$ ), which is a volatile retrograde signal. $\beta-C C$ can be rapidly converted to $\beta$-cyclocitric acid ( $\beta-C C A)$. Both $\beta-C C$ and $\beta$-CCA regulate the expression of a second subset of SORGs (SORGs II), which is distinct to those regulated by EX1. The regulation of SORGs II by $\beta-C C$ depends on the cytosolic protein methylene blue sensitive 1 (MBS1), whereas $\beta$ CCA functions independently of MBS1. $\beta-C C$ also activates the expression of genes involved in xenobiotic detoxification responses. PSI-produced ROS are thought to decrease the activities of 4-hydroxy-3-methylbut-2-enyl diphosphate synthase (HDS) and SAL1 via redox regulation, thereby enabling the accumulation of their respective substrates 2-Cmethyl-D-erythritol-2,4-cyclodiphosphate (MEcPP) and 3'-phosphoadenosine 5'-phosphate (PAP). Both these metabolites function as retrograde signals that target a broad class of genes independently of ${ }^{1} \mathrm{O}_{2}$, but are otherwise responsive to oxidative stress in chloroplasts, designated Plastid Redox Associated Nuclear Genes (PRANGs). MEcPPmediated signaling proceeds in the nucleus at least in part via the CAMTA transcription factor, but the mechanisms for intracellular transport and nuclear perception of MEcPP are still unknown. PAP transport between the chloroplast and the cytosol is mediated by PAPS/PAP transporter 1 (PAPST1) and PAPST2. In the nucleus, PAP binds to exoribonuclease enzymes (XRNs) that alter the RNA Polymerase II (Pol II) activity, thereby up-regulating a large number of PRANGs. Although direct transfer of $\mathrm{H}_{2} \mathrm{O}_{2}$ from chloroplasts to the nucleus has been observed and has been proposed to be a signaling mechanism, the nuclear $\mathrm{H}_{2} \mathrm{O}_{2}$ receptors are currently unknown. ROS overproduction in mitochondria activates an unknown protease that releases the ANAC017/ANAC013 transcription factors from their endoplasmic reticulum (ER) tethering. The truncated ANAC017/ANAC013 proteins translocate to the nucleus, where they activate the expression of the Mitochondrial Dysfunction Stimulon (MDS) genes, including Alternative Oxidase 1a (AOX1a). This mitochondrial signaling pathway is normally suppressed in the nucleus by RCD1, but activated during mitochondrial stress due to redox-mediated inactivation of RCD1 (possibly by nuclear $\mathrm{H}_{2} \mathrm{O}_{2}$ ). Another proposed regulator for this mitochondrial pathway is PAP, although the mechanism is still unidentified. Mitochondria also contain PAP and SAL1, but it is unknown whether mitochondrial SAL1 is similarly redox regulated to enable PAP to function as a mitochondrial retrograde signal. Peroxisomes are sources of various potential signaling molecules, but their connection to peroxisomal ROS and hypothetical retrograde signaling from peroxisomes is still unclear. Red arrows/lines denote ROS-induced signaling events; the blue arrow indicates a ROS detoxification step; dashed lines denote putative events with components/players yet to be experimentally demonstrated; red fonts denote ROS sensors; yellow boxes highlight signaling molecules. Abbreviations: AMP, adenosine monophosphate; ADP, adenosine diphosphate; ATP, adenosine triphosphate; HMBPP, 4-hydroxyl-3-methyl-butenyl 1-diphosphate; PAPS, 3'phosphoadenosine 5'-phosphosulfate; RNS, reactive nitrogen species. Organelles are not drawn to scale. 